\title{
CAUSALIDADE ENTRE VARIÁVEIS MACROECONÔMICAS E A RECEITA BRUTA: UMA ANÁLISE UTILIZANDO VETORES AUTORREGRESSIVOS (VAR) ${ }^{1}$
}

\section{CAUSALITY BETWEEN MACROECONOMIC VARIABLES AND GROSS REVENUE: AN ANALYSIS USING VECTORS AUTOREGRESSIVE (VAR)}

\author{
Jucimar Casimiro de Andrade ${ }^{2}$ \\ Mestrado em Administração e Desenvolvimento Rural pela Universidade Federal Rural de Pernambuco (UFRPE) \\ Técnico Administrativo em Educação do Instituto Federal de Educação, Ciência e Tecnologia da Paraíba (IFPB) \\ jucimarcandrade@gmail.com
}

André de Souza Melo

Doutor em Economia pela Universidade Federal de Pernambuco (UFPE) Professor da Universidade Federal Rural de Pernambuco (UFRPE) andredesouzam@gmail.com

\section{RESUMO}

O presente estudo teve como objetivo analisar a relação de causalidade entre um conjunto de variáveis macroeconômicas e na receita bruta em empresas do segmento de agronegócio listadas na Bolsa de Mercadorias e Futuros de São Paulo (BM\&FBovespa). Foi selecionada uma amostra de oito empresas de capital aberto com ações ativas pertencentes a diferentes ramos do agronegócio brasileiro; a escolha desse segmento se deu pela importância econômica do mesmo para a economia brasileira. Como variáveis endógenas, selecionou-se cinco variáveis: receitas brutas das respectivas companhias, PIB da agropecuária, índice de preços de produtos agropecuários (IPA), taxa básica de juros (SELIC) e taxa de câmbio (R\$/US\$). Com uso da metodologia de Vetores Autorregressivos (VAR), constatou-se que a funções impulso-resposta e decomposição variância apresentaram leituras semelhantes, ou seja, em ambos os modelos a variável PIB da agropecuária e o índice de preços de produtos agropecuários exercem significativa influência sobre a receita; em alguns modelos, a taxa básica de juros (representada pela SELIC), chegou a representar mais de $40 \%$ da variância dos erros de previsão da receita, e que um choque de $1 \%$ de erro de previsão na variável PIB da agropecuária já pode ser sentido na receita predominantemente a partir do segundo período; revelando que tais Cias. devem avaliar cuidadosamente o cenário econômico que a cerca, pois o mesmo é extremamente imprevisível, dinâmico e volátil, exigindo uma tomada de decisão tempestiva e coerente em cenários econômicos completamente adversos, principalmente no segmento de agronegócio, que representa um dos setores que mais têm impulsionando o desenvolvimento do país, mesmo ante uma conjuntura econômica desfavorável.

Palavras-chave: Finanças; Econometria; Variações Macroeconômicas.

\footnotetext{
${ }^{1}$ Artigo recebido em: 09/06/2016. Revisado por pares em: 24/08/2016. Versão final recebida em: 29/08/2016. Recomendado para publicação em: 29/08/2016 por Luiz Felipe de Araújo Pontes Girão (Editor Adjunto). Publicado em: 28/10/2016. Organização responsável pelo periódico: UFPB.

${ }^{2}$ Endereço: IFPB, Campus João Pessoa, Avenida 1ํo de maio, 720, Jaguaribe, CEP 58.015-430, João Pessoa/PB. DOI: http://dx.doi.org/10.18405/recfin20160301
} 


\section{ABSTRACT}

This study aimed to analyze the causal relationship between a set of macroeconomic variables and gross revenue in the agribusiness segment of companies listed on the Brazilian Mercantile and Futures Exchange (BM\&FBovespa). It has selected a sample of eight public companies with active stocks belonging to different branches of agribusiness; the choice of this segment was due to the economic importance of it for the brazilian economy. As endogenous variables, it was selected five variables: gross revenue of the respective companies, agriculture of gdp, price index of agricultural products (Ipa), the basic interest rate (Selic) and exchange rate (R \$ / US \$). With use of the methodology of Autoregressive Vectors (VAR), it was found that the impulse response functions and decomposition variance showed similar readings, i.e., in both models the variable gdp of agriculture and agricultural products price index significantly influence on revenues; in some models, the basic interest rate (represented by SELIC), it has come to represent more than $40 \%$ of the variance of the revenue forecast errors, and a shock of $1 \%$ of forecast error in gdp variable of agriculture can already be felt in revenue predominantly from the second period; revealing that such Cias. should carefully evaluate the economic environment that surrounds it, because it is extremely unpredictable, dynamic and volatile, requiring a decision in a timely and consistent decision completely adverse economic scenarios, especially in the agribusiness segment, which is one of the sectors that have more driving the development of the country, even at an unfavorable economic environment. Keywords: Finance; Econometrics; Macroeconomic Variables.

\section{INTRODUÇÃO}

A atual conjuntura política e econômica vivenciada pelos mercados mundiais e principalmente pela economia brasileira, vem exigindo cada vez mais capacidade de os agentes econômicos compreenderem melhor como diferentes variáveis de comportam e se relacionam entre si; forçando, em muitos segmentos econômicos, que empresas e instituições se adequem a essas novas dinâmicas e exigências mercadológicas, principalmente quanto ao futuro da economia.

Logo, a compreensão do dinamismo da atividade econômica de um país é essencial para um melhor entendimento do funcionamento e das funções do mercado financeiro, pois entendê-la, permite que se estabeleçam relações entre seus resultados agregados e o desempenho dos vários agentes econômicos que a compõem. Portanto, é por meio do conhecimento da economia que se forma uma visão mais ampla e crítica de todo o funcionamento do mercado financeiro, permitindo que se responda às diversas questões que envolvam poupança, investimentos, desenvolvimento, avaliação etc. (ASSAF NETO, 2014).

$\mathrm{O}$ ambiente econômico afeta intensamente a habilidade de as empresas operarem eficazmente e influencia suas escolhas estratégias, pois as condições econômicas modificam-se ao longo do tempo e são difíceis de ser previstas. Os períodos de crescimento acelerado podem ser seguidos por recessão. Mesmo quando as condições econômicas são favoráveis, déficits orçamentários ou outras condições provocam inquietação sobre o futuro (BATERMAN; SNELL, 2006).

Sachs e Larrain (2000, p. 5) destacam que "muitos dos temas-chave de que trata a macroeconomia envolvem variáveis como o nível geral de produção, o desemprego, a inflação e o saldo em conta corrente", ou seja, essas variáveis macroeconômicas podem ser examinadas sob diferentes perspectivas do tempo: no presente, no curto prazo, ou no longo prazo. Cada horizonte de tempo requer um modelo distinto que ajude a entender os fatores específicos que determinam as distintas variáveis macroeconômicas.

Destarte, não há como dissociar das decisões financeiras empresariais o desempenho futuro esperado da economia, o comportamento de suas taxas de juros e de seus diversos mercados financeiros. Alguns indicadores da economia, como taxas de juros de longo prazo e curto prazos, 
medidas de mercados futuros, etc., constituem-se em excelentes referências para prever a direção futura da economia, sinalizando as melhores decisões financeiras (ASSAF NETO, 2014).

Para Pimenta e Higuchi (2008) a complexidade do mercado acionário está exigindo dos investidores, além do domínio de ferramentas de análise mais sofisticada, uma visão mais sistêmica do mercado acionário, ou seja, compreender as diversas variáveis externas e como essas variáveis impactam ou interagem com outros segmentos econômicos. Assim, expandir o conhecimento sobre os mercados acionários e sobre as variáveis externas que os cercam tem implicações diretas sobre as decisões de investidores na composição de suas carteiras. Eles buscam diversificar o seu portfólio para maximizar os retornos ou para minimizar os riscos e, para tanto, o conhecimento sobre os comportamentos do mercado acionário é de suma importância.

Portanto, a presente pesquisa justifica-se pela importância econômica e estratégica que a Bolsa despenha na economia brasileira e de que os agentes econômicos que atuam nesse segmento necessitam de informações rápidas e úteis no momento do investimento, principalmente àqueles que atuam no segmento de agronegócio, um dos segmentos mais importantes e lucrativos da economia brasileira. Justifica-se, também, pela necessidade de mais estudos empíricos que sustentem a premissa de que em períodos de estresse econômico as oscilações nos agregados estabelecem algum tipo relação causal sobre os ativos e retornos esperados por companhias com capital aberto, impactando consequentemente, em outras variáveis do mercado como câmbio, índices, taxas de juros, preços de títulos e de ações, ou mais precisamente sobre o desempenho econômicofinanceiro esperado como: lucros, receitas, dividendos, em especial no agronegócio que é o foco desse estudo. Dessa forma, o presente estudo tem como objetivo analisar a relação de causalidade entre um conjunto de variáveis macroeconômicas e na receita bruta em empresas do segmento de agronegócio listadas na Bolsa de Mercadorias e Futuros de São Paulo (BM\&FBovespa).

\section{REFERECIAL TEÓRICO}

\subsection{Evidências empíricas}

Para Assaf Neto (2014), o mercado de capitais é relevante para o desenvolvimento econômico de um país, pois ele é o grande municiador de recursos permanentes para a economia. Assim, as empresas que nele negociam seus títulos são as mais importantes para o desenvolvimento econômico do país, pois possibilitam a canalização da poupança dos agentes superavitários para investimentos produtivos de grande porte, o que inclui maior circulação de numerário e investimentos estrangeiros.

Pimenta e Higuchi (2008) realizaram um estudo cujo objetivo era analisar a relação de causalidade entre um conjunto de variáveis macroeconômicas selecionadas e o retorno dos ativos no mercado acionário brasileiro, utilizando o enfoque multivariado VAR. As variáveis selecionadas foram a taxa de juros (SELIC), a taxa de câmbio (PTAX), a inflação (IPCA) e o retorno do mercado acionário brasileiro representado pelo Índice da Bolsa de Valores de São Paulo (Ibovespa). O estudo compreendeu o período entre julho de 1994, início do Plano Real, e junho de 2005. Os resultados do modelo mostraram que a taxa de câmbio (PTAX) é, dentre as variáveis selecionadas, a que apresentou nível de causalidade mais elevado em relação ao Ibovespa. Apesar disso, nenhuma das variáveis selecionadas apresentou uma relação de causalidade estatisticamente significativa em relação ao Ibovespa.

Bernardelli e Bernardelli (2016) realizaram um estudo similar utilizando o MQO com uma base de dados mensais entre 2004 a 2014, totalizando 132 amostras. Constatando que foi significativa a participação do mercado acionário na economia, o qual possui grande relevância às empresas que necessitam de recursos para produzirem, assim como aos agentes superavitários que buscam remuneração pelo capital investido. 
Visando compreender como os preços das ações respondem a choques externos, principalmente de políticas econômicas, tem crescido na literatura sobre finanças a utilização de modelos multifatoriais, como é o caso do impacto de variáveis macroeconômicas sobre a oferta pública de ações. Por meio de um Modelo Econométrico GARCH com Mudança de Regime Markoviano para séries financeiras, Ameer (2011) analisou a relação entre fatores macroeconômicos e ofertas públicas iniciais de ações (IPO) na Malásia entre 1990 a 2008. Para esse estudo ele utilizou as variáveis macroeconômicas: taxas de juros e produção industrial, concluindo que existe uma relação de causalidade entre essas variáveis e o IPO e que tal relação mostrou-se mais intensa em períodos de baixo crescimento econômico. Concluiu também que quando o governo adota aperto na política monetária, provocando aumento nas taxas de juros e consequentemente quedas nos dividendos das ações causaria efeito negativo sobre o IPO.

Através da estimação por um Modelo de Vetores Autorregressivos (VAR), Oliveira e Franscaroli (2014) pretenderam analisar quais os principais efeitos e relações das variáveis macroeconômicas e as ofertas públicas de ações no Brasil, durante o período de janeiro de 1998 a janeiro de 2012. Para esse estudo eles utilizaram como variáveis explicativas; taxa de juros, produção industrial, taxa de inflação e como variável explicada o retorno dos ativos no mercado acionário. Através da técnica de decomposição da variância e das funções de impulso-resposta eles constataram que a maior parte dos desvios causados na variância do IPO é explicada por ela mesma (cerca de $90 \%$ em 10 anos), seguida da SELIC e do IPCA. Quanto ao teste de causalidade de Granger, constaram que todas as variáveis afetam em nível a emissão de ofertas públicas e ações, com exceção do Ibovespa.

Um estudo semelhante aos anteriores, cujo objetivo era analisar se no período de estabilidade econômica brasileira, especificamente pós-implantação do regime de metas, houve uma relação significativa entre um conjunto de variáveis macroeconômicas (CÂMBIO, SELIC, PIB e IGP-M) e o índice de preços com os ativos no mercado de ações brasileiro, representado pelo IBovespa, foi realizado por Silva, Menezes e Fernandez (2011). Esse estudo foi feito através de um modelo de Vetor Auto Regressivo (VAR) e foram realizados testes de Granger para identificar as relações de causalidade. Os resultados sugerem que há uma relação significativa entre o Ibovespa e a taxa de câmbio e em menor intensidade com a Selic. Em contrapartida, o Ibovespa apresentou pouca influência sobre o PIB e no IGP-M.

Ozcan (2012) realizou no mercado turco um estudo cujo objetivo era analisar o nível de relacionamento entre um conjunto de variáveis macroeconômicas selecionadas (taxas de juros, índice de preços ao consumidor, taxa de câmbio, preços do ouro, preços do petróleo, volume de exportações e déficit em conta corrente) e o Istambul Stock Exchange (ISE) mensalmente entre os anos de 2003 a 2010. Constantando através do teste de co-integração de Johansen que existe uma relação de equilíbrio de longo prazo entre as variáveis e que o ISE apresenta uma causalidade bidirecional no sentido de Granger com as variáveis econômicas investigadas.

Recentemente, Nisha (2015) realisou um estudo no mercado indiano. Nesse trabalho, ele utilizou fatores globais e domésticos para entender como os mesmos impactavam sobre os retornos das ações da Bolsa de Valores de Bombaim (BSE). Conluindo que variáveis domésticas como taxa de juros, preços do ouro, taxa de câmbio e oferta de moeda apresentaram um impacto considerável sobre o retorno das ações da BSE. Ele observou que o retorno das ações no mercado indiano de Bombaim (BSE) é fortemente impactado por fatores macroeconômicos em nível global, o que corrobora com outros estudos, como Sigh (2010), apontando que o governo da Índia deve focar em políticas econômicas que proporcionem a estabilidade do mercado acionário tanto em nível doméstico quanto em relação ao nível global da economia indiana.

Portanto, o mercado de capitais desempenha um importante papel para a economia de um país, principalmente por aproximar o tomador de recursos do poupador de recursos, viabilizando o desenvolvimento e expansão de sua capacidade produtiva. Assim, para muitos autores, a gera- 
ção de informação no momento de um investimento é imprescindível para um investidor. Mas infelizmente, na falta dela, muitos agentes superavitários deixam de aplicar recursos por não disporem de mecanismos exatos que os auxiliem no momento do investimento com receio inclusive sobre as expectativas de retornos e sobre os rumos da economia.

\subsection{Relação entre o Desempenho Financeiro e a Taxa de Câmbio}

Em uma economia aberta, com livre trânsito de bens, serviços e capitais, a taxa de câmbio torna-se uma variável fora do controle dos Bancos Centrais, sendo definida em função do grau de confiança dos investidores estrangeiros e das variáveis estruturais de cada país. Assim, o mercado de câmbio funciona continuamente para vender, comprar ou arbitrar determinada moeda, sendo em termos mundiais a moedas mais negociadas: Dólar dos Estados Unidos, Euro da Comunidade Europeia e o Marco Alemão (BACEN, 2010).

Para Pinheiro (2014) uma queda na taxa de câmbio, ou seja, um aumento no poder de compra da moeda local, induz a um aumento nas exportações da economia. Para atender a essa nova demanda, as empresas tendem a produzir mais e a contratar mais mão-de-obra, como consequências as empresas crescem e a economia também. Assim, a bolsa de valores que reflete o desempenho da economia apresentará uma alta em função desse movimento resultante da queda na taxa de câmbio.

\subsection{Relação entre o Desempenho Financeiro e o Nível de Atividade Econômica}

O crescimento da bolsa mostra-se positivamente relacionado ao crescimento sustentável do PIB brasileiro. Para obtê-lo, não basta reduzir a taxa real de juros, pois esse é um fator importante por si só, como mencionado acima. É necessário recuperar a infraestrutura do país, principalmente na área dos transportes e energia, cujos investimentos foram insuficientes nos últimos anos, e também implementar reformas estruturais verdadeiras (MEDEIROS; RAMOS, 2004).

\subsection{Relação entre o Desempenho Financeiro e a Taxa de Juros}

A taxa de juros tem papel estratégico nas decisões dos mais variados agentes econômicos, afetando diretamente os custos financeiros das empresas e as expectativas de investimentos da economia, pois: quando as taxas de juros da economia caem, os investidores buscam novas formas de obter rentabilidade e consequentemente migram para as aplicações de renda variável, ou seja, passam a comprar mais ações e provocam alta nos preços das ações. Já quando as taxas de juros aumentam, os investidores passam a considerar a atratividade das aplicações de renda fixa e migram seus investimentos para este tipo de operações, ocasionando queda nos preços das ações; e quando as taxas de juros da economia estão baixas, as pessoas tendem a consumir mais e os custos financeiros das empresas passam a ser menores. Esses fatores geram um aumento no potencial de ganho das empresas, refletindo nas cotações de suas ações que passam a ter preços mais altos.

Para Medeiros e Ramos (2004) o impacto das taxas de juros de curto prazo no mercado é também facilmente explicável, pois, intuitivamente, aumentos na taxa de juros fortalecem a remuneração nos mercados de renda fixa, atraindo investidores para esses mercados em detrimento do mercado de renda variável. Existe, porém, um efeito oposto a esse, na medida em que aumentos na taxa de juros aumentam a dívida pública, trazendo incertezas quanto aos fundamentos macroeconômicos e à capacidade de o governo administrar a dívida, o que não favorece o mercado de capitais. 


\section{METODOLOGIA}

\subsection{Amostra}

A BM\&FBovespa disponibiliza dados financeiros de inúmeras empresas de capital aberto em diferentes segmentos econômicos. Para essa análise foram selecionadas apenas companhias de capital aberto pertencentes os segmentos de agronegócio, pois segundo o Ministério da Agricultura (2015), esse representa um dos segmentos econômicos mais importantes para o desenvolvimento do país. Destarte, foram selecionadas oito empresas que desenvolvem atividades na área de agricultura, pecuária e agroindústria. Sendo que, optou-se por essa amostra em decorrência apresentarem séries históricas consistentes e por serem bem representativas do setor de agronegócio.

\begin{tabular}{lcc}
\multicolumn{2}{c}{ Tabela 1 - Empresas listadas na BM\&FBovespa do Segmento de Agronegócio } \\
\hline \multicolumn{1}{c}{ Razão Social } & Nome de Pregão & Segmento do Agronegócio \\
\hline EUCATEX S.A. IND. E COMÉRCIO. & EUCATEX & Madeira \\
BRF FOODS S.A. & BRF & Alimentos processados \\
KLABIN S.A. & KLABIN & Papel e Celulose \\
EXCELSIOR ALIMENTOS S.A. & EXCELSIOR & Carnes e Derivados \\
CONSERVAS ODERICH & ORETICH & Indústria de Alimentos \\
JOSAPAR-JOAQUIM OLIVEIRA S.A. & JOSAPAR & Alimentos Diversos \\
RENAR MACAS S.A. & RENAR & Agricultura \\
METISA METALURGICA TIMBOENSE S.A. & METISA & Máquinas e Eq. de C. e Agrícolas \\
\hline
\end{tabular}

Fonte: Informações extraídas do site da BM\&FBovespa.

Essas companhias listadas na BM\&FBovespa desenvolvem atividades também nas áreas de agricultura e pecuária, carnes e derivados, laticínios, cigarros e fumos, papel e celulose, madeira, açúcar e álcool, máquinas agrícolas, exploração vegetal; além de atividades secundários que não são necessariamente ligadas ao agronegócio.

\subsection{Variáveis Utilizadas}

Assim, a escolha das variáveis baseou-se em três critérios: suporte na teoria sobre finanças e economia-financeira, utilização de pesquisas anteriores com metodologias parecidas ou correlatas ao tema abordado e disponibilidade de acesso à fonte de dados, sendo este último foi o mais restritivo, uma vez que, pela própria natureza da investigação a operacionalidade dos dados mostrou dificultosa.

As séries históricas de dados utilizadas neste trabalho têm periodicidade trimestral e referem-se ao intervalo do primeiro trimestre de 2003 (2003.T1) ao segundo trimestre de 2015 (2015.T2). Portanto, tem-se para essa pesquisa um total de 50 trimestres para cada companhia, sendo que cada modelo (oito modelos) têm um total de 250 observações $\left(n_{i}=250\right)$ com $k=4$, totalizando o trabalho todo com 2.000 observações $\left(n_{t}=2.000\right)$. Descrição das variáveis usadas segue abaixo:

Mercado acionário brasileiro: Receita Bruta Trimestral de cada companhia site (BM\&FBovespa /Economatica/CVM).

PIB da agropecuária: em $\mathrm{R} \$$ milhões (Contas Nacionais /IBGE-www.ibge.gov.br).

IPA: Índice de preços no atacado-produtos agropecuários (FGV-Fundação Getúlio Vargas).

Taxa real de juros: taxa OVER SELIC (www.ipeadata.gov.br).

Taxa de Câmbio: R\$ / US\$ - comercial - compra - média - R\$ (BCB-www.bcb.gov.br).

Todas essas variáveis foram utilizadas como endógenas, sendo a receita tradada como variável a ser explicada e as demais como variáveis explicativas. Esse procedimento foi feito para todas 
as companhias integrantes da amostra, o que possibilitou a estimação de oito modelos pela metodologia VAR. Quando às séries econômicas, algumas são disponíveis apenas em valores mensais, assim, para obtenção dos valores trimestrais, foram calculados pela média aritmética convencional. Destarte, todas as variáveis foram convertidas em logaritmos e por apresentarem raiz unitária conforme teste de Dickey-Fuller, foram diferencias em primeira ordem, atingindo a estacionariedade com tal procedimento.

\subsection{Modelos e Testes Utilizados}

O modelo utilizado nessa pesquisa foi o de Vetores Autorregressivos (VAR), que permite analisar a existência e/ou intensidade da relação entre variáveis, através da decomposição de variância e da análise de funções de resposta a impulso. Essa metodologia consiste basicamente numa regressão univariada em um ambiente multivariado, em que cada equação, baseia-se no modelo MQO (Mínimos Quadrados Ordinários) de variáveis auto defasadas e demais variáveis integrantes do modelo.

Num modelo de Vetores Autorregressivos (VAR) assumindo-se que todas as variáveis sejam endógenas, em que o vetor $y_{t} \in R^{n}$ no instante $t$ sendo definida apenas por seus valores defasados e pelo ruído branco $\epsilon_{t} \in R^{n}$. Assim, o modelo geral de VAR assume que $y_{t}$ depende de $y_{t-1} ; y_{t-2} \ldots y_{t-p}$ (até $p$ defasagens) ou do vetor de resíduos $\epsilon_{t}$ que estão correlacionados entres eles no instante $t$, mas não estão correlacionadas em momentos anteriores a $t$. Com base em Gujarati (2011), sua fórmula pode ser estimada como:

$$
y_{t}=c+\sum_{k=1}^{p} A_{k} y_{t-k}+e_{t}
$$

Em que,

$y_{t}=$ é um vetor $(\mathrm{n} \times 1) \in R^{n}$ no instante $t$ das variáveis empregadas no modelo;

$c=\in R^{n}$ representa o vetor de interceptos;

$A_{k}=\in R^{n x n}, k=1,2,3, \ldots, p$ são as matrizes dos coeficientes no modelo;

$e_{t}=\in R^{n x n}$ Vetor dos resíduos, tal que: $E\left[\epsilon_{t}\right]=0 \in R^{n}, E\left[\epsilon_{t} \epsilon_{t}^{T}\right]=\sum \in R^{n}$.

Antes da aplicação de qualquer modelo econométrico, o primeiro passo a ser realizado é testar a estacionariedade das variáveis. Assim, para testar a estacionariedade das séries, fora utilizado o teste de Dickey-Fuller Aumentado (ADF), objetivando encontrar a ordem de integração das variáveis de interesse, ou seja, verificar a presença ou ausência de raízes unitárias na série analisada. Segundo Santoris (2003, p.370), os testes de Dickey-Fuller Aumentado (ADF) consistem na estimação das equações pelo método MQO e apresentam-se com equações sem intercepto; com intercepto e com intercepto e tendência.

O diagnóstico do melhor modelo deve ser feito para se ter certeza de que o modelo escolhido é adequado para explicar todas as interações entre a variável e valores passados dela mesma ou de choques passados, isso significa que os resíduos devem ser desprovidos de qualquer tipo de autocorrelação, portanto, devem ter características de um ruído branco (SARTORIS, 2003). Para atingir tal objetivo, esta pesquisa utilizou dos critérios de informação de Akaike (AIC), Schwarz (SC) e Hannan-Quinn (HQC) para determinar a número de defasagens ideal do modelo.

A identificação de uma relação estatística entre duas variáveis, por mais forte que seja, não pode ser o único critério para estabelecer uma relação causal entre elas. Assim, o teste de causalidade proposto por Granger visa superar as limitações do uso de simples correlações entre variáveis e procura determinar o sentido causal entre duas variáveis, estipulando que $X$ "Granger-causa $Y^{\prime \prime}$ se valores passados de $X$ ajudam a prever o valor presente de $Y$. Assim, o teste de causalidade 
de Granger, pressupõe que a informação relevante para a previsão das variáveis utilizadas num modelo está contida unicamente nos dados da série temporal dessas variáveis. Esse teste envolve o seguinte par de regressões, conforme Gujarati (2011).

$$
\begin{aligned}
& X_{t} \sum_{i=1}^{n} \alpha_{i} Y_{t-1} \sum_{i=1}^{n} \beta_{i} X_{t-J} u_{1 t} \\
& Y_{t}=\sum_{i=1}^{n} \lambda_{i} Y_{t-1} \sum_{i=1}^{n} \delta_{i} X_{t-J} u_{2 t}
\end{aligned}
$$

Vale ressaltar que quando se analisa mais de uma variável, esta se lidando com uma causalidade bidirecional. E nesse modelo, pressupõe que os distúrbios $u_{1 t}$ e $u_{2 t}$ não são correlacionados. Assim, todas as séries foram tabuladas e organizadas com o auxílio das planilhas eletrônicas do Microsoft Excel@, e os cálculos efetuados pelo pacote econométrico GRETL-Ggnu Regression, Econometrics and Time-series. Após as respectivas tabulações dos dados, os mesmos foram organizados, processados e trabalhados com a posterior emissão e interpretação dos resultados encontrados, conforme segue detalhamento nas seções seguintes.

\section{RESULTADOS}

Nesta seção serão apresentados os resultados encontrados através das análises econométricas das séries temporais de cada empresa integrante da amostra separadamente. Portanto, será apresentado primeiramente os testes de raiz unitária (ADF Aumentado), visando verificar a ordem de integração das séries econômicas, ou seja, quantas diferenças são necessárias para que as séries se tornem estacionárias. Posteriormente será aplicado o modelo de vetores autoregressivos (VAR) com função impulso-resposta/ decomposição da variância dos erros de previsão; finalizando com o teste de Causalidade de Granger.

Em qualquer análise econométrica, o primeiro passo a ser dado é verificar a ordem de integração das séries no tempo. Pois, só é possível a estimação de um modelo de regressão confiável se as séries forem estacionárias (i) e integradas de ordem $I(0)$, ou forem integradas de mesma ordem (i) e forem $I(d)$. Esses testes relevantes são derivados da estimação pelo método dos mínimos quadrados da seguinte autorregressão entre as variáveis envolvidas.

Assim, esse procedimento foi realizado para todos os 8 modelos autoregressivos das $8 \mathrm{em}-$ presas integrantes das amostras conforme resultados expostos abaixo.

\begin{tabular}{|c|c|c|c|c|c|c|c|c|c|}
\hline \multirow{2}{*}{\multicolumn{2}{|c|}{ Lags }} & R_Eucatex & R_Brf & R_Kablin & R_Exselsior & R_Oderich & R_Josapar & R_Renar & R_Metisa \\
\hline & & 4 & 3 & 2 & 1 & 2 & 5 & 1 & 2 \\
\hline \multirow{3}{*}{$\begin{array}{c}\text { P-value } \\
\text { assintótico }\end{array}$} & $\tau n c$ & 2,93E-13 & $1,45 \mathrm{E}-10$ & $3,08 \mathrm{E}-11$ & $8,42 \mathrm{E}-08$ & 1,13E-13 & 5,68E-03 & 6,38E-02 & $4,32 \mathrm{E}-26$ \\
\hline & $\tau c$ & 4,36E-14 & 3,74E-11 & 1,35E-10 & 5,96E-06 & 1,53E-14 & $6,53 \mathrm{E}-02$ & 1,32E-02 & 2,78E-27 \\
\hline & $\tau c t$ & $2,36 \mathrm{E}-13$ & 4,43E-10 & $3,10 \mathrm{E}-10$ & 5,58E-05 & 5,58E-05 & 2,05E-01 & 3,72E-02 & 5,45E-31 \\
\hline \multirow{3}{*}{$\begin{array}{l}\text { Estatística } \\
\text { Teste }\end{array}$} & $\tau n c$ & $-7,69701$ & $-6,63094$ & $-6,90347$ & $-5,79616$ & $-7,85647$ & $-2,75614$ & $-10,54$ & $-12,4812$ \\
\hline & $\tau c$ & $-8,35734$ & $-7,34523$ & $-7,14381$ & $-5,9834$ & $-8,46015$ & $-2,75288$ & $-10,43$ & $-12,4844$ \\
\hline & $\tau c t$ & $-8,27225$ & $-7,25402$ & $-7,30531$ & $-5,91803$ & 5,31E-14 & $-2,7794$ & $-10,33$ & $-12,556$ \\
\hline Conclusão & & Rejeita $\mathrm{H}_{0}$ & Rejeita $\mathrm{H}_{0}$ & Rejeita $\mathrm{H}_{0}$ & Rejeita $\mathrm{H}_{0}$ & Rejeita $\mathrm{H}_{0}$ & Rejeita $\mathrm{H}_{0}$ & Rejeita $\mathrm{H}_{0}$ & Rejeita $\mathrm{H}_{0}$ \\
\hline
\end{tabular}

Tabela 2 - Resultado dos Testes Dickey-Fuller Aumentado

$\tau$ nc-Estatística Teste sem a constante

$\tau c t$-Estatística Teste com constante e tendência

$\tau c$-Estatística Teste com a constante

Fonte: Dados da pesquisa, 2016. 
Para a análise econométrica das séries utilizadas no modelo proposto das empresas acima, a determinação do processo autorregressivo foi realizado através dos procedimentos de Akaike (AIC), Schwarz (SC) e Hannan-Quinn (HQC), em diferentes estágios e defasagens para estimação. O teste foi realizado inicialmente em nível para as cinco variáveis analisadas nesse modelo, constando que em ambos os casos não se rejeitou a hipótese nula $\left(\mathrm{H}_{0}\right)$ de existência de raiz unitária. Quanto ao teste Dickey-Fuller Aumentado rejeitou a hipótese nula de existência de raiz unitária para ambas as variáveis em ambos os modelos, constatando que todas as séries se mostraram estacionárias em primeira diferença.

Realizado o tratamento inicial em todas as variáveis e verificado a ordem de integração conforme procedimento usuais na literatura, procedeu às estimações conforme seções seguintes.

\subsection{Modelo VAR para a empresa Eucatex S.A Indústria a Comércio.}

Buscando melhor ordenar as variáveis dentro da matriz, foi utilizada a decomposição de Cholesky na seguinte ordem: CAMBIO, SELIC, IPA, PIB-Agro e R_Eucatex, para esse primeiro modelo e para os demais. Tratamento similar observado em outros trabalhos que tratavam com variáveis do mercado financeiro (taxa de juros, câmbio, índices de bolsas, preços de ações) e do mercado nacional e internacional (exportações, importações, PIB/GDP), a exemplo de Chen (1991), Chauvin e Hirschey (1993) e Grôppo (2004). Para Burstaller (2002) essa maneira lógica de ordenação pode ser relativamente trivial, a qual não é baseada em nenhuma teoria econômica confiável, mas imagina-se ser um bom ponto de partida.

Segundo seus Relatórios Financeiros (RF), a Eucatex S.A. Ind. e Comércio é uma das maiores fornecedoras de madeira para a indústria moveleira de painéis MDP, tamburato e chapas de fibras de madeira. Produzidos com o avançado sistema contínuo, tecnologia de ponta e 100\% de madeira de eucalipto, os painéis MDP e o tamburato eucatex são utilizados na fabricação de móveis residenciais, para escritórios, hotéis e instalações comerciais.

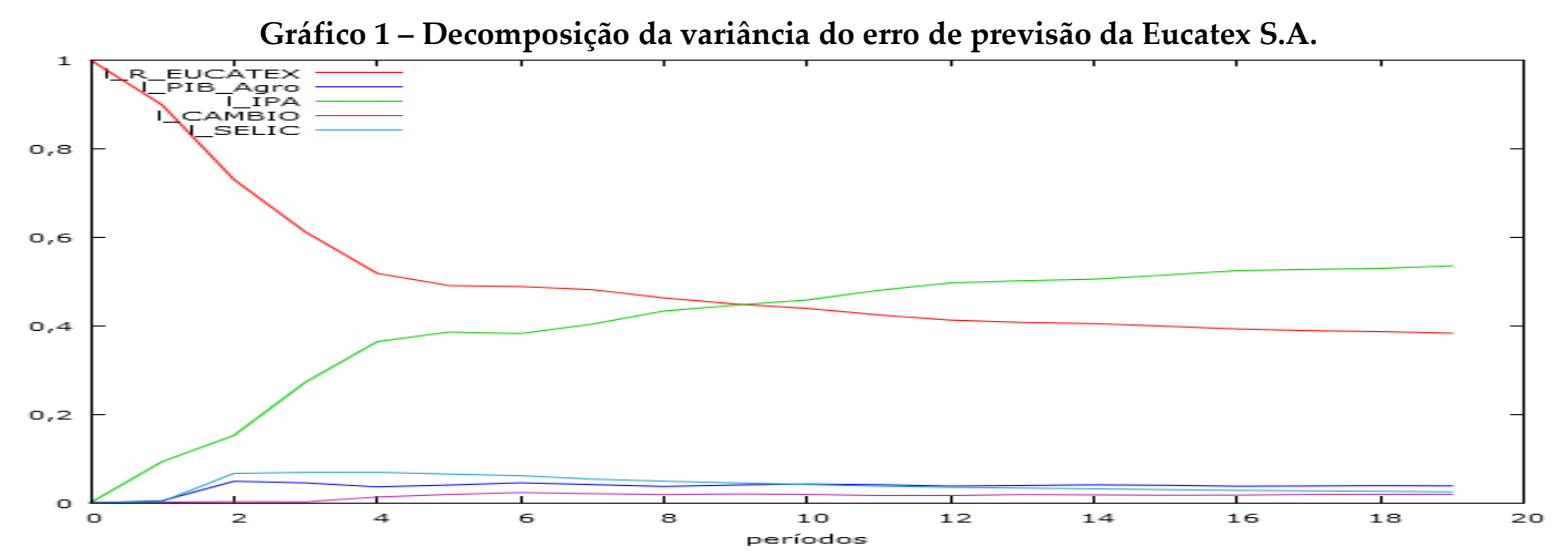

Fonte: Dados da pesquisa, 2016.

O Gráfico 1 apresenta os resultados da decomposição da variável explicada R_Eucatex, que corresponde à receita bruta da empresa Eucatex S.A. empregando para isso o procedimento de Bernanke (1994). Assim, como estimativas para 20 períodos após o choque têm que no primeiro período a variável R_Eucatex representa $100 \%$ das variações nela mesma. A partir do $10^{\circ}$ período a variável R_Eucatex explica 44,87\% dela mesma e 44,63\% é explicada pela variável IPA. Ao fim do $20^{\circ}$ período, a variável IPA responde por $53,52 \%$ das variações da variável R_Eucatex e com tendência crescente. As variáveis PIB_Agro, SELIC e CAMBIO permanecem praticamente inalteradas.

A análise da decomposição de variância do erro de previsão deixa claro o poder explicativo da variável IPA (Índice de Preços no Atacado-Produtos Agropecuários). Essa variável é um indicador econômico de abrangência nacional e é o principal componente do Índice Geral de Preços 
(IGP-DI). Sua estrutura baseia-se nas pesquisas estruturais de setores agroindustriais (25 produtos agropecuários), além das contas nacionais. Portanto, variações nos preços dos produtos agroindustriais podem impactar na receita de empresas desse mesmo segmento a partir do 9ª período, fato já esperado, conforme pesquisas anteriores de Pimenta e Huguchi (2008); Silva, Menezes e Fernandes (2011) ao trabalharem com o IGP-M e outros indicadores de preços de mercado.

É pertinente analisar também como um choque em cada variável do modelo é recebido pela variável endógena R_Eucatex. Essa relação é apresentada nos gráficos de função impulso-resposta, que mostram o quanto cada variável endógena contribui para o erro de previsão da variável de interesse.

Gráficos 2 - Gráficos da função impulso-resposta em R_Eucatex

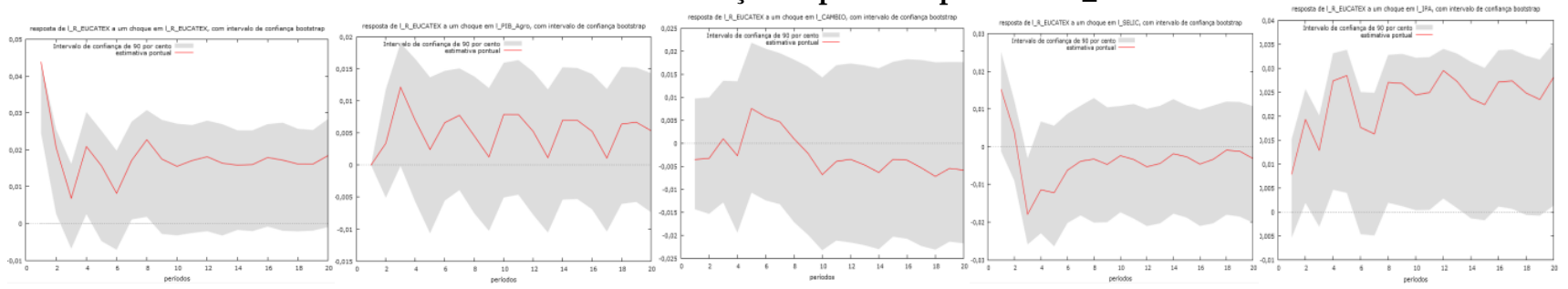

Fonte: Dados da pesquisa, 2016.

Assim, um choque estrutural na própria receita tende a responder nela mesma já no primeiro momento em torno de $+0,45 \%$ e com tendência decrescente para $-0,07 \%$ entre o segundo e o sexto períodos. Outro destaque é que um choque estrutural na taxa básica de juros (Selic) tem uma resposta negativa na receita em torno de $-0,024 \%$. Quanto às demais variáveis, sofrem um pequeno efeito sazonal positivo entre o $2^{\underline{o}}$ e o $8^{\underline{o}}$ períodos, apresentando tendência constante ao longo do décimo período.

Esse choque na variável PIB-Agro que é sentido em períodos sazonais pode ser explicado pela atividade desenvolvida por essa empresa, cujo volume de vendas e consequente receita se concentram em determinadas épocas do ano. Assim, um aumento nos preços dos produtos agroindustriais (medido pelo IPA) é sentido imediatamente pela receita da empresa Eucatex S.A. Essa variação tende a se estabilizar positivamente a partir do 9o período. Observa-se, quando há um choque no CAMBIO, a receita sofre um aumento repentino, no entanto, vai diminuindo ao longo do tempo até se estabilizar no $10^{\circ}$ período. Um choque na variável SELIC provoca uma resposta repentina na receita, a partir do $4^{\mathrm{o}}$ período essa tendência tende a se normalizar negativamente.

Tabela 3 - Teste de causalidade de Granger da Eucatex S.A.

\begin{tabular}{l|c|c|c}
\hline \multicolumn{1}{c|}{ Hipótese Nula } & Estatística F & Teste & Decisão \\
\hline 1_R_Eucatex Does Not Granger Cause 1_R_Eucatex & 5,99003 & 0,0025 & Rejeita $^{* * *}$ \\
\hline 1_R_PIB_Agro Does Not Granger Cause 1_R_Eucatex & 3,8432 & 0,0193 & Rejeita $^{* *}$ \\
\hline 1_R_IPA Does Not Granger Cause 1_R_Eucatex & 4,223 & 0,0132 & Rejeita $^{* *}$ \\
\hline 1_R_CAMBIO Does Not Granger Cause 1_R_Eucatex & 0,13829 & 0,9363 & Não Rejeita $^{*}$ \\
\hline 1_R_SELIC Does Not Granger Cause 1_R_Eucatex & 4,85552 & 0,0023 & Rejeita $^{* * *}$ \\
\hline
\end{tabular}

Notas: Cálculos realizados com 3 lags.

Estatística Durbin-Watson para esse teste foi de: 2,041488 (Limite de 1,85 - 2,15)

* Significante a $10 \%$

**Significante a $5 \%$

***Significante a $1 \%$

Fonte: Dados da pesquisa, 2016 
Essa estatística foi feita com três defasagens usando o modelo de autorregressão vetorial. Para esta estatística de teste, o GRETL utiliza os mínimos quadrados ordinários e assume como hipóteses nulas que todas as defasagens de: 1_R_Eucatex, 1_PIB_Agro, 1_IPA, 1_CAMBIO e 1_SELIC são iguais a zero $(\beta 1=\beta 2=\beta 3=\beta 4=\beta 5=0)$. Portanto, assumindo um nível de significância de $5 \%$ (mais comum na literatura) a única variável que não causa no sentido de Granger na receita da empresa Eucatex S.A. é a taxa de câmbio. Por ser uma empresa que exporta grande parte de sua produção para o mercado externo, esperava-se que a taxa de câmbio exercesse uma relação causal (positiva ou negativa) com a receita total, no entanto não foi o que se observou. Tal fato pode ser explicado pela pouca dependência que a mesma tem de insumos do mercado internacional, uma vez que praticamente toda a produção (plantio e processamento de madeira) e também um grande volume de vendas são realizados no mercado nacional, o que segundo seus relatórios financeiros gera uma compensação entre as trocas temporais.

\subsection{Modelo VAR para a empresa BRF Foods S.A.}

A BRF Foods S.A. nasce a partir da associação entre Perdigão e Sadia, uma das maiores companhias global do setor alimentício, é também uma das maiores exportadoras mundiais de ave; atuando nos seguintes segmentos: carnes, alimentos processados de carnes, lácteos, margarinas, massas, pizzas e vegetais congelados, com marcas consagradas como Sadia, Perdigão e Qualy, entre outras.

Gráfico 3 - Decomposição da variância do erro de previsão da BRF Foods S.A.

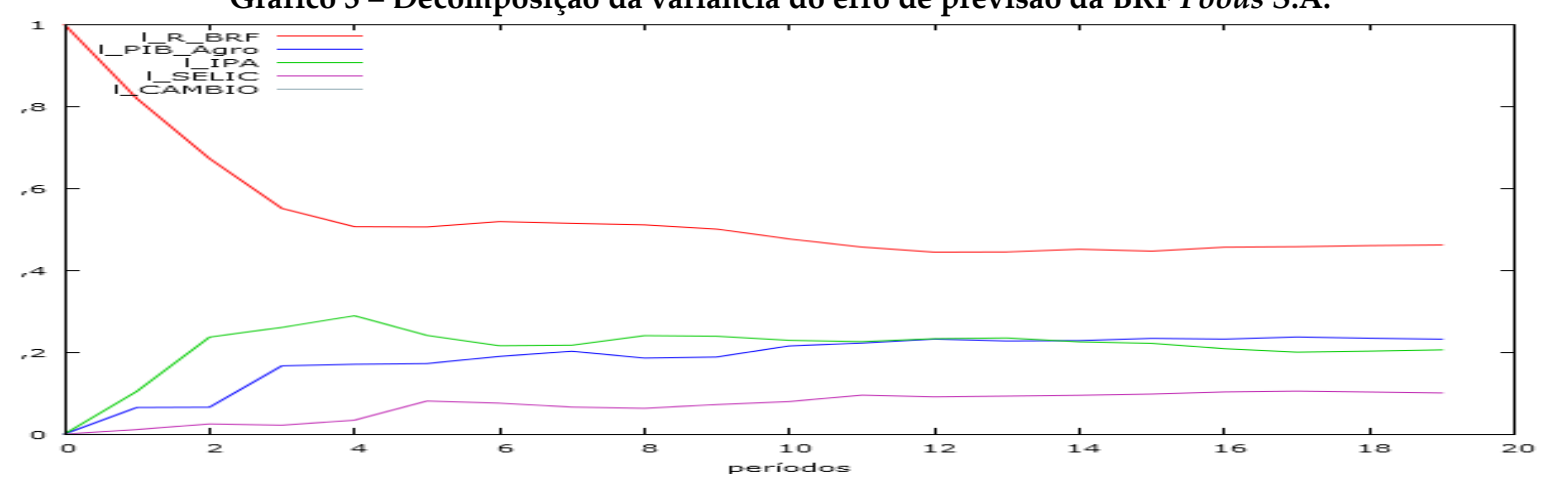

Fonte: Dados da pesquisa, 2016.

O Gráfico 3 apresenta os resultados da decomposição da variável explicada R_BRF, que corresponde a receita bruta da empresa BRF Foods S.A. Assim, como estimativas para 20 períodos após o choque tem-se que no primeiro período a variável R_BRF representa $100 \%$ das variações nela mesma. No sétimo período 18,97\% é explicado pelo PIB_Agro, 21,56\% pelo IPA e 7,54\% pela SELIC. Ao fim do $20^{\circ}$ período $46,19 \%$ é explicada por ela mesma, 23,18\% pelo PIB-Agro e 20,56\% pelo IPA. Nessa parte da análise a variável câmbio permaneceu praticamente inalterada. Assim, a análise da decomposição de variância do erro de previsão evidencia, mais uma vez, nesse segundo modelo, o poder explicativo da variável IPA (Índice de Preços no Atacado-Produtos Agropecuários) e também da variável PIB-Agro, que diferentemente do modelo anterior mostrou-se mais influente.

A análise da decomposição de variância do erro de previsão evidencia, mais uma vez, nesse segundo modelo, o poder explicativo da variável IPA (Índice de Preços no Atacado-Produtos Agropecuários) e também da variável PIB-Agro, que diferentemente do modelo anterior mostrouse mais influente. Portanto, variações nos preços dos produtos agroindustriais e na atividade econômica no contexto do agronegócio devem ser levadas em conta pela alta administração dessa 
corporação, uma vez que, mudanças abruptas podem impactar na receita negativamente caso não haja um planejamento estratégico adequado.

Gráficos 4: Gráficos da função impulso-resposta em R_BRF

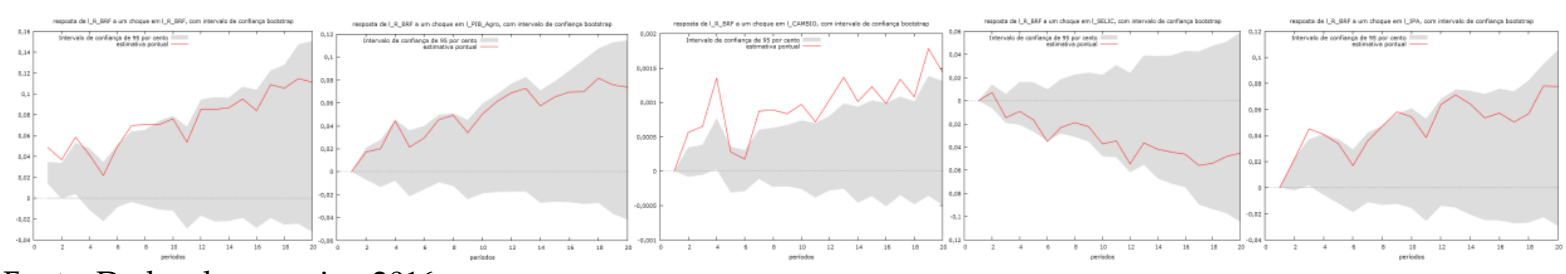

Fonte: Dados da pesquisa, 2016.

Um choque na variável $R \_B R F$ afeta ela mesma em intervalos de $0,02 \%$ a $0,12 \%$ com tendência crescente positiva. Um choque na variável PIB_Agro, IPA e CAMBIO têm respostas parecidas com crescimento positivo. Quanto à SELIC, um aumento na taxa básica de juros tende a diminuir a receita dessa empresa com tendência negativa. Portanto, a variação positiva das variáveis PIB-Agro e IPA pode ser explicada, pois, um aumento dos preços de produtos agropecuários e também na atividade econômica desse segmento podem significar melhores vendas e maiores lucros para empresas que operam no segmento agroindustrial.

Tabela 4 - Teste de causalidade de Granger da BRF Foods S.A.

\begin{tabular}{l|c|c|c}
\hline \multicolumn{1}{c|}{ Hipótese Nula } & Estatística F & Teste & Decisão \\
\hline 1_R_BRF Does Not Granger Cause 1_R_BRF & 6,941 & 0,0007 & Rejeita $^{* * *}$ \\
\hline 1_R_PIB_Agro Does Not Granger Cause 1_R_BRF & 0,89529 & 0,4821 & Não Rejeita $^{* *}$ \\
\hline 1_R_IPA Does Not Granger Cause 1_R_BRF & 1,8276 & 0,1564 & Não Rejeita** $^{*}$ \\
\hline l_R_CAMBIO Does Not Granger Cause 1_R_BRF & 0,33231 & 0,2247 & Não Rejeita $^{* *}$ \\
\hline l_R_SELIC Does Not Granger Cause 1_R_BRF & 1,5318 & 0,0023 & Rejeita $^{* * *}$ \\
\hline
\end{tabular}

Notas: Cálculos realizados com 3 lags

Estatística Durbin-Watson para esse teste foi de: 1,905447 (Limite de 1,85 - 2,15)

* Significante a $10 \%$

**Significante a $5 \%$

***Significante a $1 \%$

Fonte: Dados da pesquisa, 2016.

Nas análises anteriores a taxa de juros básica mostrava-se relacionada com receita dessa empresa. Fato confirmado nos relatórios financeiros da mesma ao apontar que as negociações para a compra da Sadia pela Perdigão tiveram início em 2008, com o então presidente José Antônio do Prado Fay. O sucesso da fusão, anunciado oficialmente em Maio de 2009, deu origem à BRF, que seguiu sob o comando de Fay. Isso é o que explica o aumento da receita da BRF Foods S.A. nos relatórios financeiros da BM\&FBovespa em mais de $60 \%$, e para manter os níveis de crescimento e produção a mesma recorreu a empréstimos e financiamos, o que de fato explica a causalidade da taxa básica de juros sobre seu desempenho econômico-financeiro.

\subsection{Modelo VAR para a empresa Klabin S.A.}

A Klabin S.A. é um grupo industrial brasileiro, especializada em papéis, cartões para embalagens, embalagens de papelão ondulado_e sacos industriais e organizada em quatro unidades de negócios (Florestal, Papéis, Embalagens de Papelão Ondulado e Sacos Industriais). 


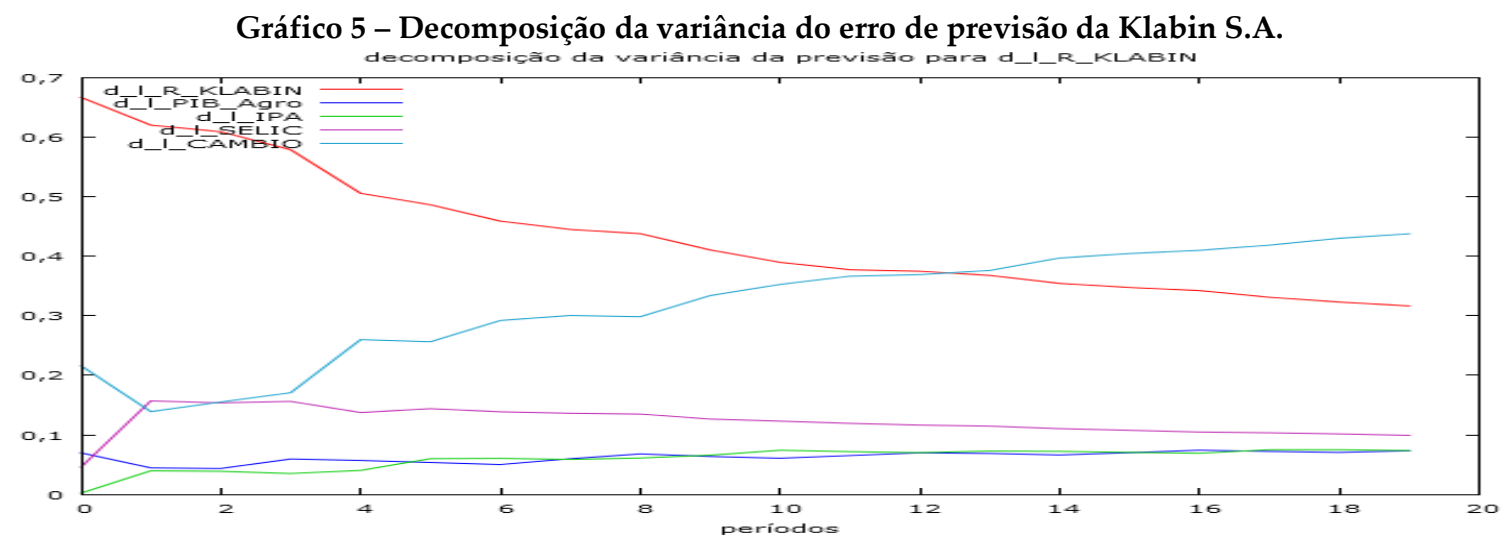

Fonte: Dados da pesquisa, 2016.

Assim, como estimativas para 20 períodos após o choque, tem-se que no primeiro período a variável R_Klabin representa $66,68 \% \%$ das variações nela mesma. A partir do $12^{a}$ período a variável que mais impacta na variação da receita é a taxa de câmbio, chegando a 43,77\% no fim do $20^{\circ}$ período. As demais variáveis permaneceram praticamente constantes, com pequenas variações apenas no primeiro período. Esses resultados corroboram com o estudo de Sousa (2011), onde o mesmo utilizou o modelo APT da área financeira para precificação de ativos. Nesse estudo ele encontrou uma relação significativa entre os coeficientes beta de sensibilidade das variáveis câmbio e da taxa de juros básica (representadas pela SELIC) com retorno acionário da mesma empresa aqui analisada.

Gráficos 6 - Gráficos da função impulso-resposta em R_KLABIN

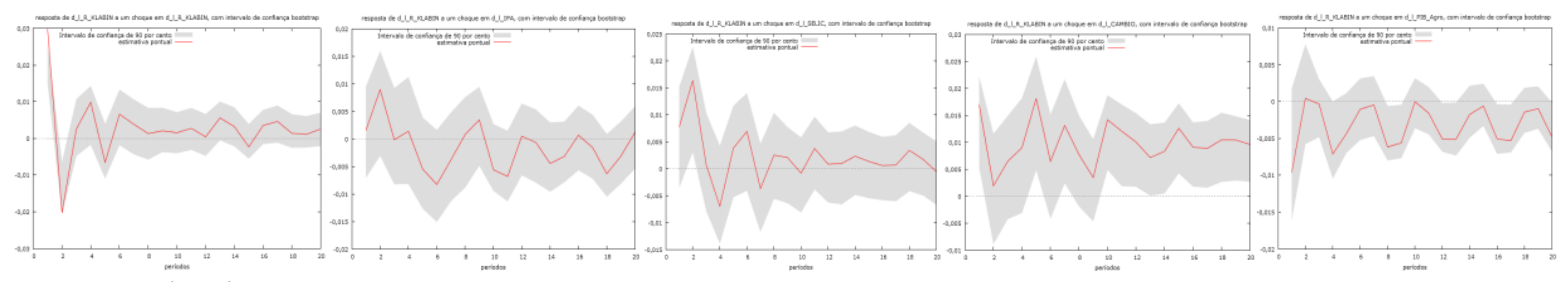

Fonte: Dados da pesquisa, 2016.

Um choque na própria variável (R_Klabin) e na taxa básica de juros é sentida no primeiro momento, apontando para uma tendência constante a partir do $10^{\circ}$ período após o choque. Igualmente à análise anterior, na decomposição da variância, a variável câmbio mostrou-se influente, pois o choque é captado em períodos sazonais de maneira positiva até 20 períodos à frente. Segundo os relatórios financeiros da Klabin S.A, durante o segundo trimestre, a desaceleração da economia no mercado interno também impactou o mercado de toras de madeira, pressionando as serrarias e laminadoras a ampliar a exportação de seus produtos. Todavia, com a taxa de câmbio mais elevada, a maior exportação dos clientes de madeira da Klabin foi refletida no crescimento das vendas ao longo do período. Neste contexto de desaquecimento nos mercados nacionais e melhores condições no mercado externo, o aumento no volume de vendas da Klabin, compatível com sua crescente capacidade de produção, foi basicamente direcionado a mercados de fora do Brasil, ampliando de maneira significativa as vendas de papéis na exportação e isso é o que tem justificado a forte influência da taxa de câmbio nas transações dessa corporação. 
Tabela 5 - Teste de causalidade de Granger da Klabin S.A.

\begin{tabular}{l|c|c|c}
\hline \multicolumn{1}{c|}{ Hipótese Nula } & Estatística F & Teste & Decisão \\
\hline 1_R_Klabin Does Not Granger Cause 1_R_Klabin & 19,747 & 0,0001 & Rejeita*** $^{*}$ \\
\hline 1_R_PIB_Agro Does Not Granger Cause 1_R_Klabin & 6,4141 & 0,0151 & Rejeita** $^{*}$ \\
\hline 1_R_IPA Does Not Granger Cause 1_R_Klabin & 3,0351 & 0,0886 & Rejeita* $^{*}$ \\
\hline 1_R_CAMBIO Does Not Granger Cause 1_R_Klabin & 2,1247 & 0,1522 & Não Rejeita* $^{*}$ \\
\hline 1_R_SELIC Does Not Granger Cause 1_R_Klabin & 1,9809 & 0,1665 & Não Rejeita $^{*}$
\end{tabular}

Notas: Cálculos realizados com 1 lag

Estatística Durbin-Watson para esse teste foi de: 2,002219 (Limite de 1,85 - 2,15)

* Significante a $10 \%$

**Significante a $5 \%$

***Significante a $1 \%$

Fonte: Dados da pesquisa, 2016.

Portanto, as variáveis que causam no sentido de Granger na receita foram: ela mesma a 1\%, PIB-Agro a 5\% e IPA a 10\%. Apesar de na análise anterior sobre decomposição da variância, a significância dos coeficientes das variáveis PIB_Agro e o IPA não terem sido relevantes se comparados a outras variáveis como câmbio, nesse teste, essas duas variáveis causam no sentido de Granger na variável R_Klabin, isso pode ser explicado pois a atividade desenvolvida por essa corporação é tipicamente de base agrícola e florestal. Assim, mudanças em segmentos ligados direta ou indiretamente ao segmento agropecuário e agroindustrial devem ser considerados pela alta administração como medida de mitigação do risco sistemático ou não diversificável (variações na economia).

\subsection{Modelo VAR para a empresa Exselsior S.A.}

A Excelsior Alimentos S.A. é uma empresa gaúcha que desenvolve produtos, industrializando carne suína e de frango para a mesa dos brasileiros. São presuntos, fatiados em geral, patês, salsichas, linguiças e congelados: pizzas, lasanhas, empanados e pão de queijo.

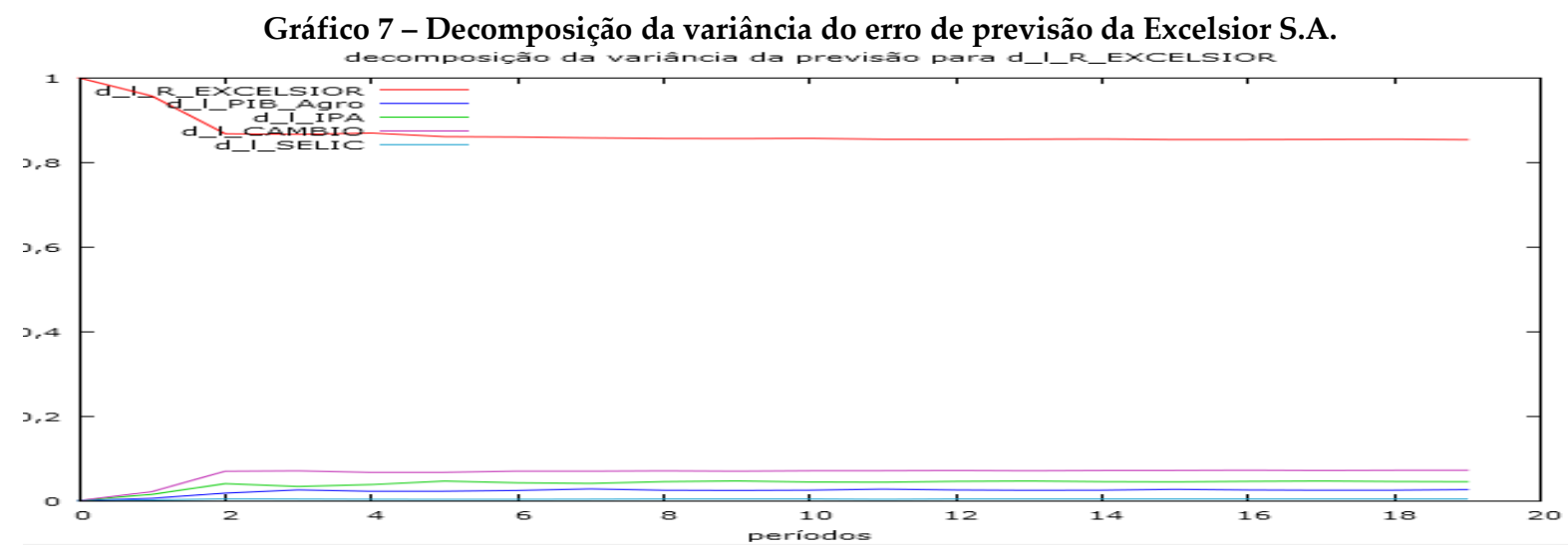

Fonte: Dados da pesquisa, 2016.

Para esse modelo, as variáveis SELIC e CAMBIO não se mostraram significantes, fato que contrasta com os resultados de Callado et al (2010), num estudo no segmento de Alimentos e Bebidas, em que constataram que a taxa de juros e de câmbio, mostraram-se relacionadas com o Índice Bovespa para empresas desse segmento. Um resultado também semelhante ao de Grôppo (2004), que constatou que a taxa básica de juros é a que mais impacta no Ibovespa e que um choque na taxa de câmbio real leva à redução do Ibovespa já num primeiro momento.

Assim, como estimativas para 20 períodos após o choque tem-se que do primeiro período até o último, a variável receita é a que mais impacta sobre as variações dela mesma. As demais 
variáveis permaneceram praticamente constantes, com pequenas variações apenas no primeiro período. Esse resultado corrobora com os estudos realizados por Rahman e Uddin (2009), que encontram uma relação negativa entre o retorno dos ativos e a taxa de inflação.

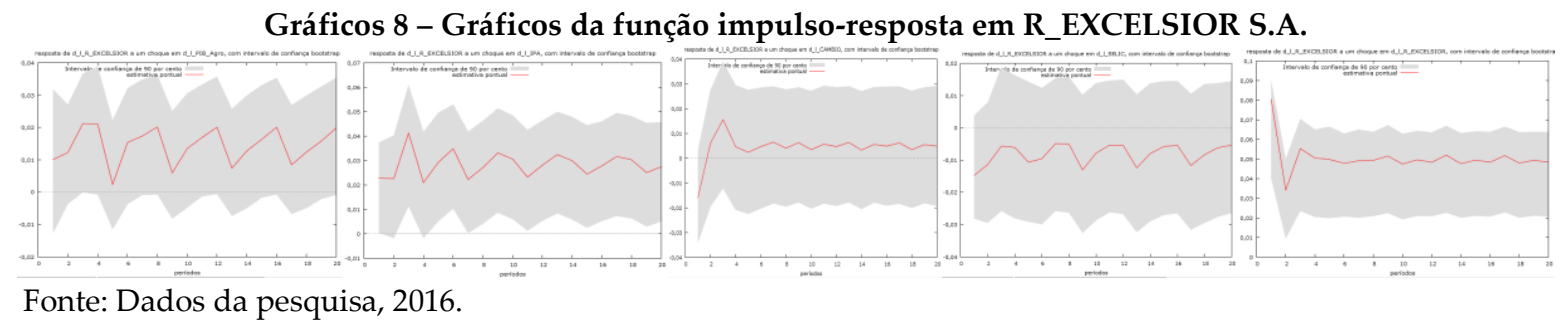

Mais uma vez para esse modelo as variáveis PIB_Agro, IPA e a própria receita mostraramse bastante significantes, pois um choque na própria receita tende a ser sentido por ela mesma de forma intensa já no primeiro período; assim como a taxa de câmbio real, que apesar de uma tendência constante a partir do quarto período após o choque, pode ser sentida já nos primeiros períodos. Isso se explica, pois segundo os relatórios financeiros da Excelsior Alimentos S.A. as operações da Companhia estão concentradas no mercado interno e, consequentemente seus fluxos de caixa não estão sujeitos a variações cambiais de moedas estrangeiras, sendo assim, não há risco associado à variação de moedas. Dessa forma, a Companhia não está apresentando análise de sensibilidade quantitativa mais elevada referente a risco da exposição às variações cambiais de moedas estrangeiras.

Tabela 6 - Teste de causalidade de Granger da Excelsior S.A.

\begin{tabular}{|c|c|c|c|}
\hline Hipótese Nula & Estatística F & Teste & Decisão \\
\hline 1_R_Excelsior Does Not Granger Cause 1_R_Excelsior & 1,1104 & 0,3603 & Não Rejeita* \\
\hline 1_R_PIB_Agro Does Not Granger Causel_R_Excelsior & 6,1967 & 0,0021 & Rejeita*** \\
\hline 1_R_IPA Does Not Granger Cause 1_R_Excelsior & 2,664 & 0,0813 & Rejeita* $^{*}$ \\
\hline 1_R_CAMBIO Does Not Granger Cause 1_R_Excelsior & 2,664 & 0,0658 & Rejeita* $^{*}$ \\
\hline 1_R_SELIC Does Not Granger Cause 1_R_Excelsior & 1,0317 & 0,3926 & Não Rejeita* \\
\hline $\begin{array}{l}\text { Notas: Cálculos realizados com } 3 \text { lags } \\
\text { Estatística Durbin-Watson para esse teste foi de: 1,5544 } \\
\text { Estatística Ljung-Box Q' = 1,73712 com p-valor = P(Qui } \\
\text { * Significante a } 10 \% \\
\text { **Significante a } 5 \% \\
* * \text { Significante a } 1 \%\end{array}$ & $\begin{array}{l}\text { Limite de 1,85 } \\
\operatorname{drado}(3)>1,73\end{array}$ & $=0,629$ & \\
\hline
\end{tabular}

As variáveis que causam no sentido de Granger na receita são: ela mesma a 1\%, PIB-Agro a $1 \%$ e as variáveis IPA e CAMBIO a 10\% de significância. Tal situação pode ser explicada, pois, os Relatórios Financeiros dessa companhia demonstram que há um risco constante de possíveis flutuações oriundas nas taxas de juros incidentes sobre os seus ativos e passivos financeiros. Assim, visando minimizar possíveis impactos advindos dessas oscilações, a mesma adota a política de diversificação nas linhas de crédito, alternando a contratação com taxas variáveis e taxas fixas. $\mathrm{Na}$ data das presentes informações contábeis intermediárias, os instrumentos financeiros da Companhia, remunerados a uma taxa de juros, estão a seguir apresentados pelo valor contábil. 


\subsection{Modelo VAR para a empresa Oderich S.A.}

Os Relatórios administrativos apontam que a Conservas Oderich S.A. fabrica a mais completa linha de conservas de carnes, legumes, compotas de frutas, molhos, pickles, atomatados e maioneses do Brasil. As carnes bovinas, suínas e de frango, mais de 150 toneladas por dia, são fornecidas por frigoríficos que atendem as normas e padrões internacionais.

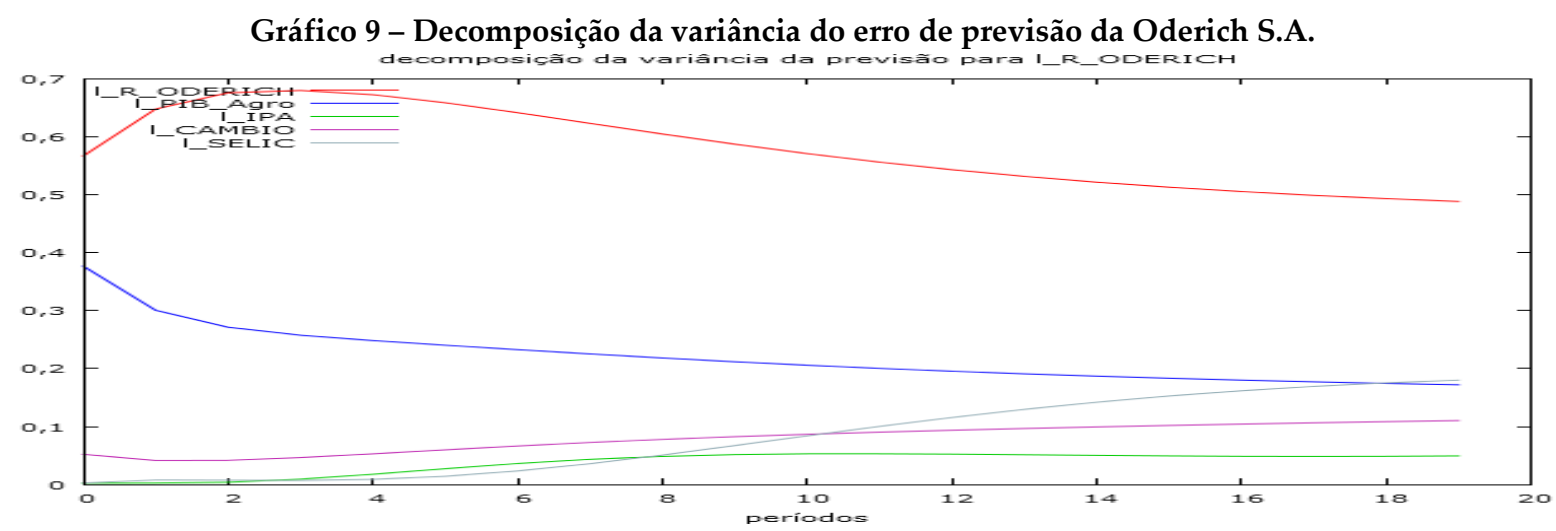

Fonte: Dados da pesquisa, 2016.

No primeiro momento $56,67 \%$ das variações da receita são atribuídas a ela mesma, seguido da variável PIB_Agro que corresponde a 37,67\%. Essa variação segue sem muitas alterações até o $20^{\circ}$ período em que a variável SELIC passa a representar 18,01\% dessas variações. Segundo os relatórios financeiros, as oscilações de preços e do câmbio são constantes, e essas oscilações podem provocar alterações substanciais nas receitas e nos custos, o que pode incorrer em perdas, principalmente pelas flutuações dessas taxas. Assim, para mitigar esse risco, sua administração acompanha permanentemente os mercados locais e estrangeiros, buscando antecipar-se ao movimento de preços; além de possuir contratos no mercado de derivativos, ou seja, operações "swap" de proteção da taxa de juros.

Gráficos 10 - Gráficos da função impulso-resposta em R_Oderich S.A.

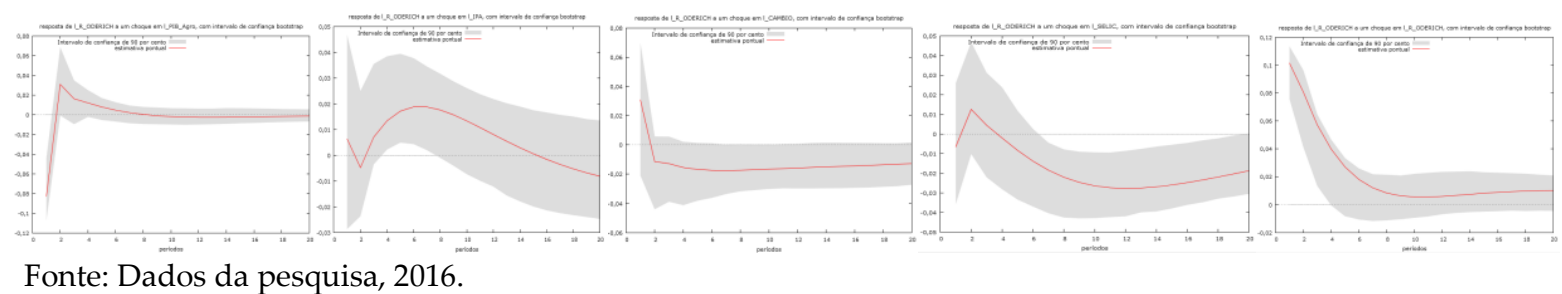

A variável R_Oderich responde a um choque na variável PIB_Agro já no primeiro momento, a partir do $8^{\circ}$ período após o choque observa-se que tal impacto é praticamente nulo. Um choque na variável IPA é sentido positivamente até p $12^{\circ}$ período, seguindo tendência negativa até $20^{\circ}$ período. Um choque na taxa básica de juros é sentido negativamente a partir do $2^{o}$ período.

Para Kruger e Peter (2013) tal situação pode ser explicada pois ao prever a queda de lucros, os investidores do mercado de ações, especialmente os institucionais, venderão parte de suas ações e migrarão para outros mercados mais líquidos e menos arriscados, entre eles, o tradicional mercado de depósitos bancários, tal como os fundos de renda fixa, muitas vezes desvinculados do mercado acionário e geralmente com remuneração atrelada aos títulos públicos federais, ou seja, remunerados à taxa Selic. 
Tabela 7 - Teste de causalidade de Granger da Oderich S.A.

\begin{tabular}{l|c|c|c}
\hline \multicolumn{1}{c|}{ Hipótese Nula } & Estatística F & Teste & Decisão \\
\hline 1_R_Oderich Does Not Granger Cause 1_R_Oderich & 26,679 & 0 & Rejeita*** $^{* *}$ \\
\hline 1_R_PIB_Agro Does Not Granger Cause 1_R_Oderich & 15,123 & 0,0004 & Rejeita*** $^{* *}$ \\
\hline 1_R_IPA Does Not Granger Cause 1_R_Oderich & 1,2954 & 0,2615 & Não Rejeita* $^{*}$ \\
\hline 1_R_CAMBIO Does Not Granger Cause 1_R_Oderich & 3,6414 & 0,0632 & Rejeita $^{*}$ \\
\hline 1_R_SELIC Does Not Granger Cause 1_R_Oderich & 1,5688 & 0,2173 & Não Rejeita* $^{*}$ \\
\hline
\end{tabular}

Notas: Cálculos realizados com 1 lag.

Estatística Durbin-Watson para esse teste foi de: 2,048387 (Limite de 1,85 - 2,15)

Estatística Ljung-Box Q' $=0,243156$ com p-valor $=P($ Qui-quadrado(1) $>0,243156)=0,622$

* Significante a $10 \%$

**Significante a $5 \%$

***Significante a $1 \%$

Fonte: Dados da pesquisa, 2016

As variáveis que causam no sentido de Granger na receita são: ela mesma e a variável PIB_Agro a 1\%, além da variável CAMBIO desde que se assuma uma significância de $10 \%$. As variáveis SELIC e IPA não se mostraram significantes, portanto, não causaram no sentido de Granger na receita. Assim, o resultado bastante significante da variável PIB_Agro, corrobora com os resultados encontrados por Rahman e Uddin (2009) para o mercado da Índia, Paquistão e Bangladesh no subcontinente indiano, mas contrastam com os de Albuquerque (2014) em que a variável mais causou no sentido de Granger na receita (representado pelo faturamento bruto disponível na BM\&FBovespa) foram a SELIC seguida pelo PIB, que não se mostrou tão significante.

\subsection{Modelo VAR para a empresa Josapar S.A.}

Josapar-Joaquim Oliveira S.A é uma empresa de produtos alimentícios. Atualmente está presente em pontos de venda em todo o Brasil, além de ter seus produtos exportados para mais de 40 países. Entre os destaques da empresa estão as marcas Tio João, Meu Biju e SupraSoy, além de outras marcas e linhas que você pode conferir em nossa sessão de produtos.

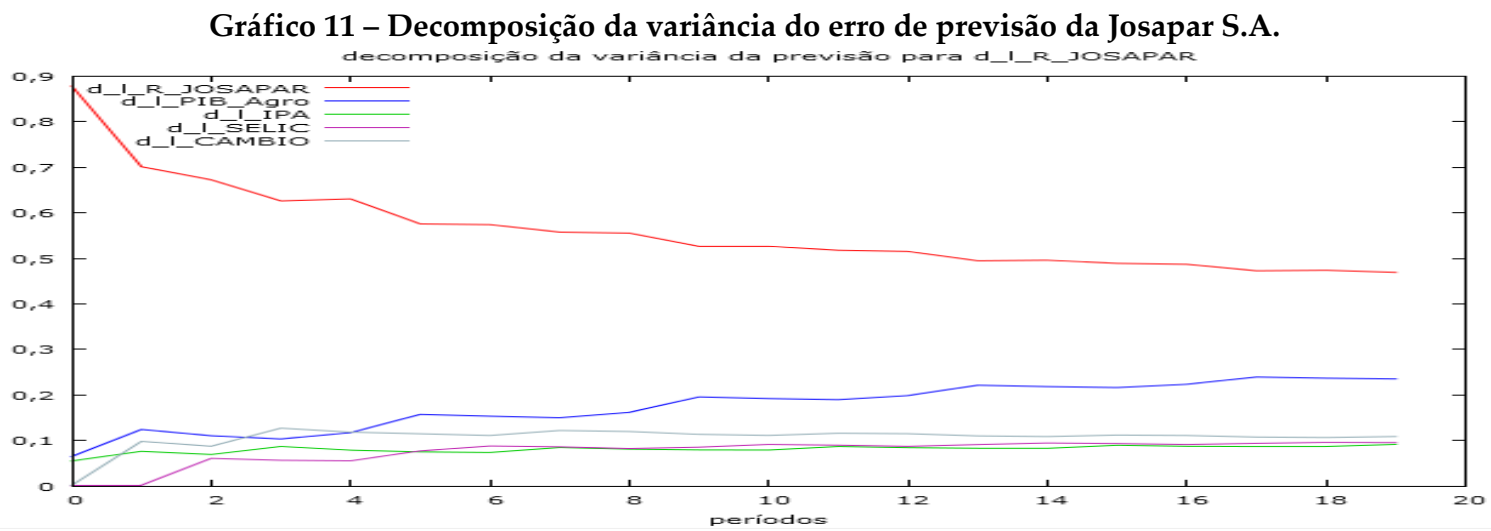

Fonte: Dados da pesquisa, 2016.

Assim, como estimativas para 20 períodos após o choque tem-se que do primeiro período até o último, a variável receita é a que mais impacta sobre as variações dela mesma, representando 87,84\% das variações nela mesma já no primeiro período, enquanto que a variável PIB_Agro passa a representar $23,5 \%$ das variações da receita ao final do $20^{\circ}$ período.

Segundo os relatórios financeiros na Josapar Participações S.A. a companhia está exposta a muitos riscos, principalmente os riscos cambiais e de mercado. Assim, os riscos cambiais, decorrentes de operações de compra e venda no mercado externo, estão completamente atrelados a prazos e volumes que se equivalem, o que forma uma proteção natural para eventuais variações 
futuras. Os riscos de mercado são administrados pelo planejamento de compras, onde se toma por base o nível de preço dos insumos que viabiliza a comercialização das mercadorias no mercado local dentro dos padrões de margem de lucro esperados e os prazos de entrega prováveis. Isso explica em parte a pouca influência das variáveis mercadológicas sobre os resultados dessa companhia.

\section{Gráficos 12 - Gráficos da função impulso-resposta em R_Josapar S.A.}

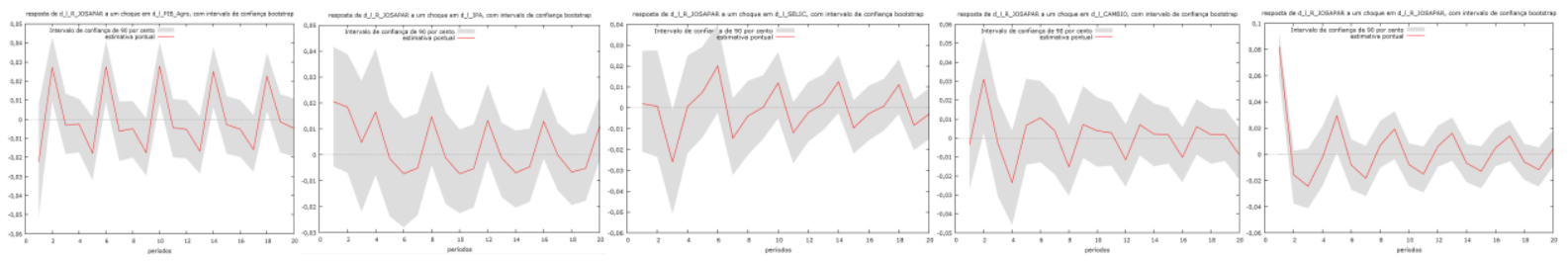

Fonte: Dados da pesquisa, 2016.

Os gráficos de função impulso-resposta revelam que as variáveis oscilam positiva e negativamente em momentos de pico e depressão ao longo do eixo desde o primeiro período após o choque até o $20^{\circ}$ período, principalmente para a variável CAMBIO. Isso se explica, pois segundo os relatórios financeiros da Josapar Participações S.A. a companhia tem como regra geral a não contratação de linhas de crédito em moeda estrangeira, de forma a não ficar sujeita ao risco de flutuações do mercado de câmbio, financiando majoritariamente sua operação por linhas de crédito em moeda nacional, taxas pré-fixadas ou pós-fixadas por indexadores brasileiros (CDI e TJLP) mais spread bancário.

Tabela 8 - Teste de causalidade de Granger da Josapar S.A.

\begin{tabular}{|c|c|c|c|}
\hline Hipótese Nula & Estatística $\mathbf{F}$ & Teste & Decisão \\
\hline 1_R_Josapar Does Not Granger Cause 1_R_Josapar & 4,6173 & 0,009 & Rejeita*** \\
\hline 1_R_PIB_Agro Does Not Granger Cause 1_R_Josapar & 1,8787 & 0,1545 & Não Rejeita* \\
\hline 1_R_IPA Does Not Granger Cause 1_R_Josapar & 1,82 & 0,1648 & Não Rejeita* \\
\hline 1_R_CAMBIO Does Not Granger Cause 1_R_Josapar & 2,0189 & 0,1324 & Não Rejeita* \\
\hline 1_R_SELIC Does Not Granger Cause 1_R_Josapar & 1,0483 & 0,3856 & Não Rejeita* \\
\hline $\begin{array}{l}\text { Notas: Cálculos realizados com } 3 \text { lags } \\
\text { Estatística Durbin-Watson para esse teste foi de: 1,917 } \\
\text { Estatística Ljung-Box Q' }=0,0863022 \text { com p-valor }=\mathrm{P}( \\
\text { * Significante a } 10 \% \\
* \text { Significante a } 5 \% \\
* * * \text { Significante a } 1 \%\end{array}$ & $\begin{array}{l}\text { (Limite de 1,85 } \\
\text { quadrado(3) > }\end{array}$ & $\begin{array}{l}\text { 5) } \\
3022)=0\end{array}$ & \\
\hline
\end{tabular}

Portanto, a única variável que causa no sentido de Granger na receita é o PIB_Agro a 1\%, as demais mostraram-se pouco significantes. Resultado compatível com os estudos de Rahman e Uddin (2009) no mercado asiático, ao utilizarem as variáveis: preços das ações e taxa de câmbio, constatando que não houve uma relação de causalidade entre elas. Mas oposto aos resultados de Ozcan (2012) que encontrou uma causalidade bidirecional para a Bolsa de Valores de Istambul na Turquia.

\subsection{Modelo VAR para a empresa Renar S.A.}

A Renar Maçãs S.A. caracteriza-se pelo cultivo e pela produção de maçãs para a indústria alimentícia, sendo seus principais produtos a maçã desidratada e a polpa congelada, além do cultivo de mudas. 


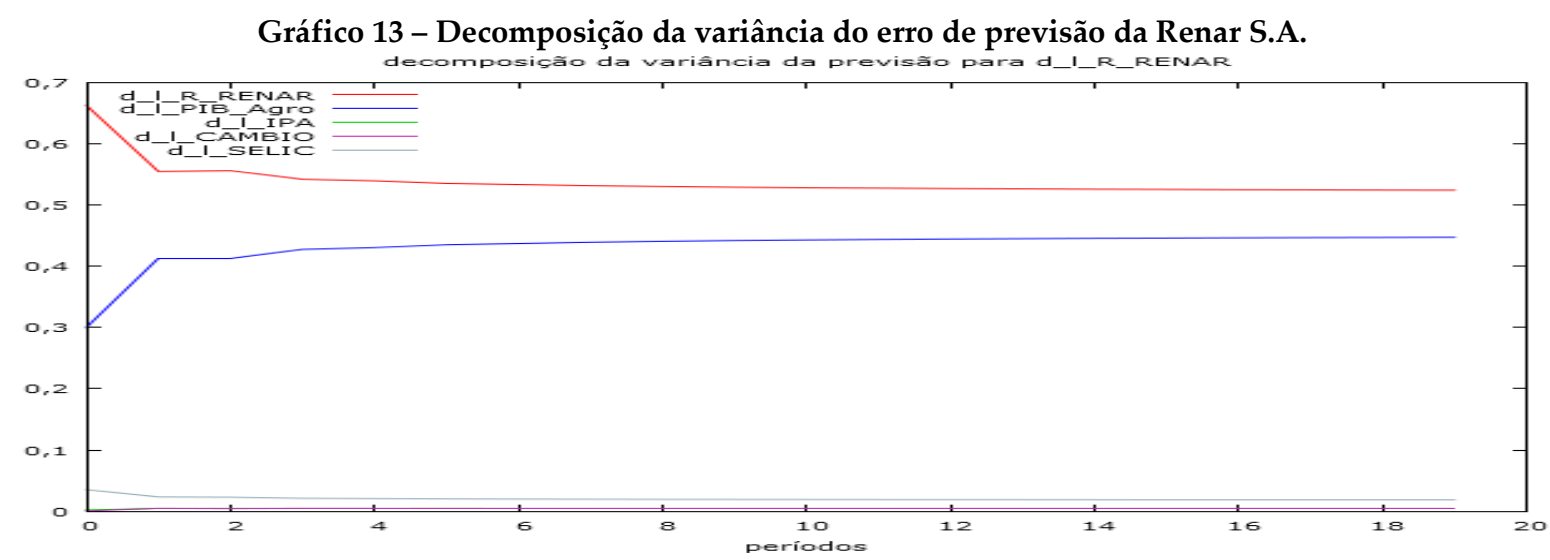

Fonte: Dados da pesquisa, 2016.

O Gráfico 13 apresenta os resultados da decomposição da variável explicada R_Renar, que corresponde à receita bruta da empresa Renar S.A. empregando para isso o procedimento de Bernanke (1994). Assim, no primeiro período 66,27\% das variações de R_Renar são explicadas por ela mesma, 29,98\% pelo PIB_Agro, a SELIC com 3,51\% e o IPA com 0,198\%. Ao fim do $20^{\circ}$ período, o PIB_Agro passa a responder por aproximadamente $44,73 \%$ das variações da receita.

\section{Gráficos 14 - Gráficos da função impulso-resposta em R_Renar S.A.}

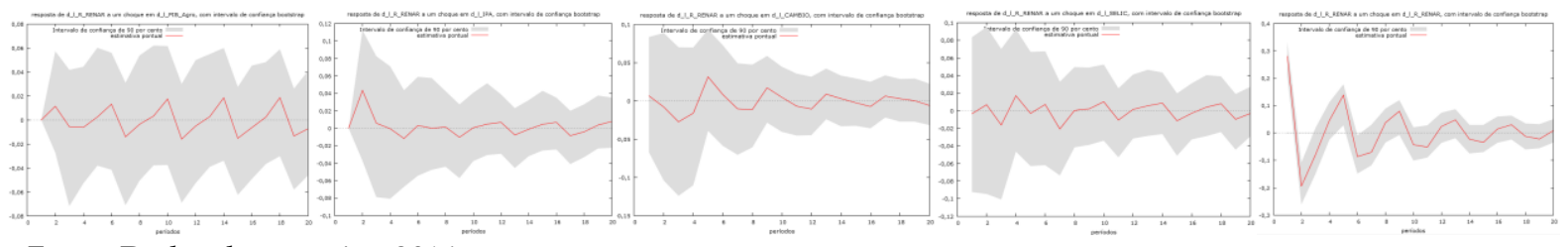

Fonte: Dados da pesquisa, 2016.

Nesse modelo, para as cinco variáveis analisadas não se constatou uma mudança muito significativa. A partir do primeiro período após o choque, ambas seguem em curso oscilando positiva ou negativamente ao redor do eixo zero, mas sem maiores alterações que mereçam ser destacadas. Tal situação pode ser em parte explicada, pois, a Companhia monitora continuamente seus riscos de mercado relacionados com variação cambial, oscilação nas taxas de juros, volatilidade nos preços das frutas no mercado nacional e internacional e os riscos de crédito, inerentes aos seus negócios. Esse monitoramento é acompanhado pela Administração e pelo Conselho de Administração. Visando mitigar riscos, afirma também que efetua empréstimos vinculados a moeda estrangeira (ACC - Adiantamento de Contrato de Câmbio e ACE - Adiantamento de Contrato de Exportação), cuja quitação, registrada no Banco Central, é feita diretamente por esses recebíveis em moeda estrangeira. Outra forma utilizada pela Companhia para minimizar os riscos financeiros e de mercado é a contratação de instrumentos financeiros derivativos (NDFs), além de monitorar continuamente as taxas de juros do mercado, com o objetivo de avaliar a eventual necessidade de contratação de derivativos para se proteger da volatilidade dessas taxas.

Apesar de para esse modelo a variável PIB não apresentar-se significante, Medeiros e Ramos (2004), destacam que o efeito positivo da atividade econômica do agronegócio sobre o mercado de capitais parece incontroverso. Aumentos do PIB da Agropecuária refletem o aquecimento dos diferentes segmentos ligados à agricultura e pecuária. Portanto, uma situação econômica aquecida para o agronegócio tende a estimular investimentos, pois os investidores têm maiores perspectivas de lucros, o que poderia elevar receitas, lucros com consequência de maior distribuição de dividendos aos acionistas e investidores. 
Tabela 9 - Teste de causalidade de Granger da Renar S.A.

\begin{tabular}{l|c|c|c}
\hline \multicolumn{1}{c|}{ Hipótese Nula } & Estatística F & Teste & Decisão \\
\hline 1_R_Renar Does Not Granger Cause 1_R_Renar & 12,089 & 0 & Reject $^{* * *}$ \\
\hline 1_R_PIB_Agro Does Not Granger Cause 1_R_Renar & 0,085376 & 0,9675 & Does Not Reject $^{*}$ \\
\hline 1_R_IPA Does Not Granger Cause 1_R_Renar & 0,50469 & 0,682 & Does Not Reject $^{*}$ \\
\hline 1_R_CAMBIO Does Not Granger Cause 1_R_Renar & 0,19169 & 0,9012 & Does Not Reject $^{*}$ \\
\hline 1_R_SELIC Does Not Granger Cause 1_R_Renar & 1,0317 & 0,3926 & Does Not Reject $^{*}$ \\
\hline
\end{tabular}

Note: Cálculos realizados com 3 lags

Estatística Durbin-Watson para esse teste foi de: 1,941968 (Limite de 1,85 - 2,15)

Estatística Ljung-Box $Q^{\prime}=6,96285$ com p-valor $=P($ Qui-quadrado $(4)>6,96285)=0,138$

* Significante a $10 \%$

**Significante a $5 \%$

***Significante a $1 \%$

Fonte: Dados da pesquisa, 2016.

\subsection{Modelo VAR para a empresa Metisa S.A.}

Segundo seu site, a Metisa Metalúrgica Timboense S.A. comercializa ferramentas agrícolas, lâminas para corte de pedras ornamentais, ferramentas de penetração de solo, acessórios ferroviários, peças para implementos rodoviários, além de ferramentas manuais e arruelas.

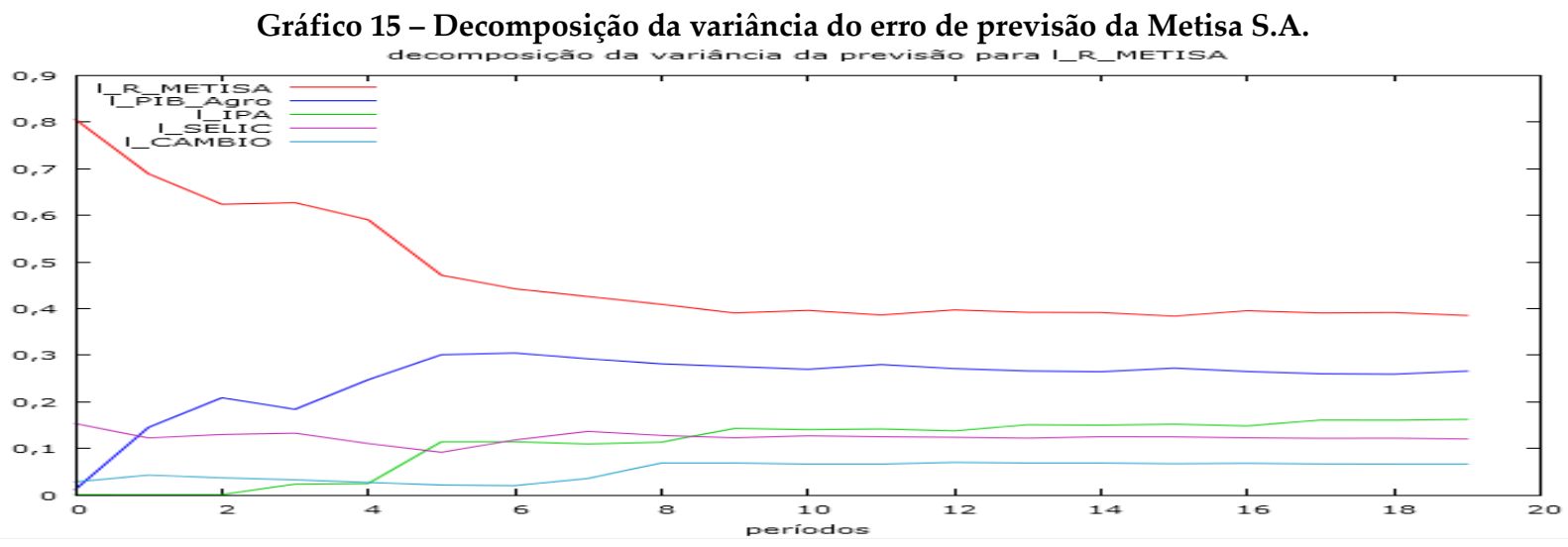

Fonte: Dados da pesquisa, 2016.

No primeiro período, a própria receita responde por 80,79\% das variações nela mesma e a SELIC por $17,19 \%$. A partir do sétimo período, a variável CAMBIO começa a exercer maior participação sobre as variações da receita, chegando a representar $21,72 \%$ ao final do $20^{\circ}$ período. Tal situação pode ser explicada, pois, as vendas da Metisa se dirigem a diversos setores da economia, sendo os principais o setor agrícola, o setor de construção civil, a mineração e o setor de construção e conservação de estradas. Assim, o principal risco de mercado a que a mesma está exposta é o risco cambial, risco esse naturalmente decorrente de sua atividade exportadora. Esse risco advém dos efeitos da variação cambial sobre as contas a receber de clientes no exterior, sobre o valor dos contratos de exportação firmados e sobre o valor dos Adiantamentos de Contratos de Câmbio (ACC). No encerramento do exercício de 2014, os valores sujeitos à variação cambial eram:

- Contas a receber de clientes no exterior em torno de $\mathrm{R} \$ 25.662 .707,00$

- Adiantamentos sobre Contratos de Câmbio (ACC/ACE) de R\$28.036.611,00 


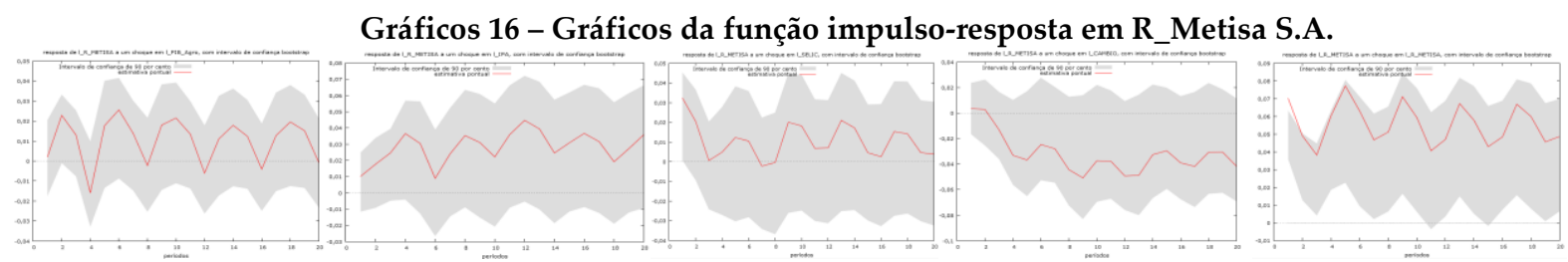

Fonte: Dados da pesquisa, 2016.

Um choque no câmbio tem uma resposta negativa na receita logo de imediato em torno de $0,03 \%$, e esse impacto segue em intervalos oscilantes até o $20^{\circ}$ período após o choque. Um choque no PIB_Agro e IPA é sentido positivamente pela variável receita também em intervalos temporais. De todas as variáveis, os valores passados da própria receita são os que mais impactam nas variações dela mesma, em torno de $+0,04 \%$ a $+0,08 \%$. Esses resultados corroboram com Pimenta e Higuchi (2008) ao constatarem que a taxa de câmbio (PTAX) foi a que apresentou o maior impacto com o índice Bovespa, enquanto que, a taxa de juros não mostrou-se significante, mas contrastam com os resultados de Albuquerque et al (2014) e com também com Grôppo (2004), ao constatarem que a taxa básica de juros é a que mais impacta no Ibovespa e que um choque na taxa de câmbio real leva à redução do Ibovespa já num primeiro momento.

Tabela 10 - Teste de Causalidade de Granger da Metisa S.A.

\begin{tabular}{l|c|c|c}
\hline \multicolumn{1}{c|}{ Hipótese Nula } & Estatística F & Teste & Decisão \\
\hline l_R_Metisa Does Not Granger Cause 1_R_Metisa & 8,0682 & 0,0003 & Reject $^{* * *}$ \\
\hline 1_R_PIB_Agro Does Not Granger Cause 1_R_Metisa & 4,689 & 0,0058 & Reject $^{* * *}$ \\
\hline 1_R_IPA Does Not Granger Cause 1_R_Metisa & 1,652 & 0,1926 & Does Not Reject $^{*}$ \\
\hline l_R_CAMBIO Does Not Granger Cause 1_R_Metisa & 0,13155 & 0,9694 & Does Not Reject* $^{*}$ \\
\hline l_R_SELIC Does Not Granger Cause 1_R_Metisa & 0,46117 & 0,7635 & Does Not Reject $^{*}$ \\
\hline
\end{tabular}

Note: Cálculos realizados com 4 lags

Estatística Durbin-Watson para esse teste foi de: 2,163984 (Limite de 1,85 - 2,15)

Estatística Ljung-Box Q' = 1,2519 com p-valor $=P($ Qui-quadrado(4) > 1,2519) =0,869

* Significante a $10 \%$

**Significante a $5 \%$

***Significante a $1 \%$

Fonte: Dados da pesquisa, 2016.

As variáveis que causam no sentido de Granger na receita são: ela mesma a 1\%, PIB-Agro a $1 \%$, as demais mostraram-se insignificantes (mais que 10\%). Esse teste corrobora com Albuquerque et al (2014) ao analisar a relação entre algumas variáveis selecionadas e o segmento de construção civil da BM\&FBovespa; constatando que as variáveis que mais causaram no sentido de Granger na receita (representado pelo faturamento bruto disponível na BM\&FBovespa) foram a SELIC seguida do PIB.

\section{CONCLUSÃO}

Estudos sobre diferentes aspectos do mercado financeiro e de sua relação com as variáveis econômicas fundamentais remontam desde aproximadamente a década de 60, e vêm evoluindo paulatinamente, ganhando adaptações e sendo debatidos arduamente do contexto das finanças corporativas em diferentes esferas econômicas e recentemente no contexto do agronegócio, uma atividade que desempenha um importante papel na economia brasileira.

Portanto, os resultados obtidos nesta investigação, buscaram melhor compreender a dinâmica das relações entre as variáveis que integram as diferentes cadeias do agronegócio brasileiro, objetivando fornecer possíveis direções para os agentes econômicos que atuam direta ou indiretamente com esses segmentos (produtores, traders, exportadores, importadores, corretoras), como 
forma de subsidiar a tomada de decisão, especialmente em temos de incerteza quanto ao futuro do país e/ou impactos das decisões políticas que serão tomadas a médio ou longo prazos.

Como observado nas análises, o PIB da agropecuária e o Índice de Preços de Produtos Agropecuários (Ipa), exerceram significativa influência sobre a receita das companhias analisadas, mesmo naquela cuja atividade principal não era de base agrícola ou pecuária. Isso mostra que o crescimento da bolsa está positivamente relacionado ao crescimento sustentável do PIB brasileiro. Por isso, alertam Medeiros e Ramos (2004), é necessário recuperar a infraestrutura do país, principalmente na área dos transportes e energia, cujos investimentos foram insuficientes nos últimos anos, e também implementar reformas estruturais verdadeiras que viabilizem o desenvolvimento desse segmento econômico imprescindível ao crescimento do país.

A decomposição da variância dos erros de previsão revelou, como comentado anteriormente que o PIB e o Ipa explicam em grande parte as variações na receita, sendo que para a Eucatex S.A. o Ipa chegou a representar aproximadamente $44,63 \%$ a partir do nono período e para a corporação Klabin S.A. a taxa de câmbio representou cerca de 39,77\% das variações da receita da mesma a partir do $12^{\circ}$ período. A taxa básica de juros também se mostrou significante em alguns modelos, especialmente para a Oderich S.A. que atua basicamente no mercado nacional e necessita de capital interno para investimento em produção e expansão.

Os testes econométricos foram realizados de maneira exaustiva para todas as 2.000 observações das oito empresas da amostra, revelando características peculiares de cada segmento que só puderam ser compreendidas pelas análises dos relatórios financeiros e administrativos. Assim, usadas em nível ou em primeiras diferenças, em alguns casos pôde-se entender como esses segmentos de correlacionam e em muitos casos se causam, no intuito de oferecer evidências empíricas aos operadores do mercado financeiro sobre como a dinâmica entre essas variáveis financeiras e econômicas tendem a se comportar, possibilitando aos mesmos, melhores condições de planejamento estratégico, especificamente no mercado de commodities agrícolas.

Acredita-se que o ambiente tecnológico e demográfico, que correspondem às tecnologias utilizadas na produção, na comercialização, às necessidades e gostos de consumo dos clientes, são fatores críticos que podem exercer influência, mas que não puderam ser analisadas neste primeiro momento. Assim, recomenda-se uma análise mais profunda com utilização de mais variáveis que mensurem a atividade econômica e financeira de outros segmentos do agronegócio que tenham capital aberto e que possam ser potencialmente impactantes nos preços das commodities agrícolas ou dos resultados brutos/líquidos de empresas, inclusive com utilização de variáveis do mercado internacional como o índice de volatilidade Vix (CBOE Volatility Index) da bolsa de Chicago, também conhecido como "medidor do medo" de Wall Street, uma vez que, o mesmo é referência no mercado bursátil de commodities agrícolas (café, soja, milho).

Por fim, conclui-se com essa investigação que os agentes econômicos devem avaliar cuidadosamente o cenário econômico nacional e internacional antes de investir no mercado de capitais. O mesmo, como observado, é extremamente imprevisível, dinâmico e volátil, em que se exige a tomada de decisões tempestivas e certas em cenários econômicos completamente adversos, como os atuais do Brasil. Como afirma Pinheiro (2014), é um mercado instigante que remunera bem as mentes brilhantes que nele ousam aplicar seu suor e capital, mas com pouco espaço para amadorismo ou para quem não aceita altos riscos.

\section{REFERÊNCIAS}

ALBUQUERQUE, P. H.M.; SILVA, L. C.; MALUF, Y. S. Estimação da influência de variáveis macroeconômicas sobre o faturamento de organizações siderúrgicas usando ARMAX. Gestão e Produção, v.3, n.1, p.648-659. 2014. 
AMEER, Rashid. Macroeconomic factors and initial public offerings (IPOS) in Malaysia. Asian Academy of Management Journal of Accounting and Finance (AAMJAF), v.8, n.1, p.41-67. 2012.

ASSAF, A. N. Curso de Administração Financeira. 3ª̣ed. São Paulo: Atlas. 2014.

BARON, D. P. A model of the demand for investment bank adving and distribution services for new issues. Journal of Finance, v.1, n.37, 955-976. 1982.

BATERMAN, Thomas S.; SNELL, Scott A. Administração. São Paulo: Atlas, 2006.

BERNARDELI, L. V.; BERNARDELI, A. G. Análise sobre a relação do mercado acionário com as variáveis macroeconômicas no período de 2004 a 2014. Revista Evidenciação Contábil e Finanças, João Pessoa, v.4, n.1, p. 4-17, jan./abr. 2016.

BERNANKE, B.; GERTLER, M.; GILCHRIST, S. The financial accelerator and the flight to quality, NBER Working Paper, v.1, n. 4789. 1994.

BURGSTALLER, J. Are stock returns a leading indicator for real macroeconomic developments? Working Paper, v.1, n.207. 2002.

CHAUVIN, K. W.; HIRSCHEY, M. (1993). Advertising, R\&D expenditures and the market value of the firm. Financial Management, v.22, n.4, p.128-140. 1993.

CHEN, N.F. Financial Investment Opportunities and the Macroeconomy. Journal of Finance, v.46, n.2, p.529-544. 1991.

GRANGER, C. W. J.; HUANG, B. N.; YANG, C. W. Abivariate causality between stock prices and exchange rates: Evidence from the recent Asia. Discussion Paper, v.1, n.54,p.98-09, University of California, San Diego, Department of Economics. 1998.

GRÔPPO, G. S. Causalidade das variáveis macroeconômicas sobre o Ibovespa. 2014. 124f. Dissertação (Mestrado em Economia Aplicada) - Programa de Pós-Graduação em Economia. Escola Superior de Agricultura Luiz de Queiroz, Universidade de São Paulo, Piracicaba, 2004.

GUJARATI, D. N; PORTER, D. C. Econometria Básica. 5aㅗ ed. Porto Alegre: Bookman, 2011.

KRUGER, S. D.; PETRI, S. M. Análise comparativa da causalidade de medidas de desempenho das empresas da BM\&FBovespa no período de 2000 a 2010. Revista de Contabilidade do Mestrado em Ciências Contábeis da UERJ, Rio de Janeiro, v.18, n.1, p.3. 2013.

MEDEIROS, O. R.; RAMOS, F. C. Determinantes do Desempenho e Volatilidade na Bovespa: um Estudo Empírico. In: Congresso USP de Controladoria e Contabilidade, n.4. São Paulo. Anais... São Paulo/SP: Controladoria e Contabilidade. 2004.

NISCHA, N. Impact of macroeconomic variables on stock returns: Evidence from Bombay Stock Exchange. Journal of Investment and Management. Munich Personal RePEc Archive.v.3, n.38980, p.20-52. 2012. 
NUNES, M.S.; COSTA, N. C. A.; MEURER, R. A relação entre o mercado de ações e as variáveis macroeconômicas: uma análise econométrica para o Brasil. Revista Brasileira de Economia, v.59, n.4. 2005.

OLIVEIRA, J. C. T.; FRANSCAROLI, B. F. Impacto dos fatores macroeconômicos na emissão de ações na bolsa de valores. Gestão, Finanças e Contabilidade, v.4, n.1. 2014.

OZCAN, Ahmet. The Relationship Between Macroeconomic Variables and ISE Industry Index. International Journal of Economics and Financial Issues, v.2, n.2, p. 184-189. 2012.

PIMENTA JUNIOR, T.; HIGUCHI, R. H. Variáveis macroeconômicas e o Ibovespa: um estudo da relação de causalidade. Revista Eletrônica de Administração (REAd ), v.60, n.4. 2008.

PINHEIRO, J. L. Mercado de Capitais - Fundamentos e Técnicas. 7ª Ed. São Paulo: Atlas. 2014.

RAHMAN, M. L.; UDDIN, J. Dynamic Relationship between Stock Prices and Exchange Rates: evidence from Three South Asian Countries. International Business Research, v.2, n.2. 2009.

SANTORIS, Alexandre. Estatística e introdução à econometria. São Paulo: Saraiva, 2003.

SICH, D. Causal Relationship Between Macro-Economic Variables and Stock Market: a case of study for India. Pakistan Journal of Social Sciences (PJSS), v.30, n.2, p.263-274. 2010.

SILVA, J. C. A.; MENEZES, G.; FERNANDEZ, R. N. Uma análise VAR das relações entre o mercado de ações e as variáveis macroeconômicas para o Brasil. Revista Economia e Desenvolvimento, v.1, n.23, 2011.

SOUSA, P. T. Z. Análise da eficiência o mercado acionário brasileiro: um estudo do setor de papel e celulose através de modelos APT. 2011. 96f. Dissertação (Mestrado em Administração e Desenvolvimento Rural)-Programa de Pós-Graduação em Administração e Desenvolvimento Rural. UFRPE, RecifePe, 2011. 